\title{
Condições Atmosféricas Associadas a Eventos de Ressaca no Litoral Sul e do Sudeste do Brasil durante o El Niño 2015/2016
}

\author{
Jeferson Prietsch Machado $^{1}$ (D), Gustavo Santos Barbosa Miranda ${ }^{2}$, Luiz Felippe Gozzo ${ }^{2,3}$ (D), \\ Maria de Souza Custódio ${ }^{2,3}$ \\ ${ }^{1}$ Instituto de Oceanografia, Programa de Pós-Graduação em Oceanologia, Universidade Federal \\ do Rio Grande, Rio Grande, RS, Brasil. \\ ${ }^{2}$ Departamento de Física, Faculdade de Ciências de Bauru, Universidade Estadual Paulista \\ "Júlio de Mesquita Filho", Bauru, SP, Brasil. \\ ${ }^{3}$ Centro de Meteorologia de Bauru, Faculdade de Ciências de Bauru, Universidade Estadual \\ Paulista "Júlio de Mesquita Filho”, Bauru, SP, Brasil.
}

Recebido em: 11 de Março de 2018 - Aceito em: 26 de Abril de 2019

\begin{abstract}
Resumo
Os sistemas meteorológicos que ocasionam tempestades acompanhadas de ventos fortes, como frentes frias e ciclones extratropicais e subtropicais, muitas vezes interferem na condição de agitação do mar. Como consequência, o nível do mar pode se elevar extraordinariamente causando inundações na costa. Os anos de 2015 e 2016 foram caracterizados pela ocorrência da fase positiva do fenômeno El Niño - Oscilação Sul, com intensidade muito forte. O Sul do Brasil apresentou maiores condições de instabilidade atmosférica, com frequentes passagens de sistemas frontais e formação de ciclones extratropicais, interferindo nas condições de mar do litoral Sul e do Sudeste do Brasil. Diante do exposto, este estudo objetivou avaliar as condições atmosféricas durante eventos de ressaca no litoral Sul e do Sudeste do Brasil durante o El Niño 2015/2016, através de informações presentes nos Avisos de Mau Tempo, emitidos pelo Centro de Hidrografia da Marinha do Brasil. Por meio desses avisos e dos dados de reanálise do ERA-Interim, foram analisadas as distribuições por área marítima, por mês e por estação do ano, bem como foi realizada a análise de campos sinóticos plotados em superfície para os 12 eventos de maior destaque. Como resultados, os meses de outono e de inverno registraram as maiores ocorrências de ressaca em ambas as áreas, durante o período do El Niño 2015/2016. De um modo geral, quatro padrões atmosféricos favoráveis aos eventos de ressaca foram identificados, em função da atuação de ciclones extratropicais e a atuação de sistemas de alta pressão pós-frontal.
\end{abstract}

Palavras-chave: El Niño, Ressaca, sistemas atmosféricos.

\section{Atmospheric Conditions Associated to Rough Sea Events in the South And Southeastern Coast of Brazil During 2015/2016 El Niño}

\begin{abstract}
The weather systems that cause storms accompanied by strong winds, such as cold fronts and extratropical and subtropical cyclones, often interfere with the sea condition. As a consequence, sea levels can rise dramatically causing coastal flooding. The 2015 and 2016 years were characterized by the occurrence of the positive phase of the phenomenon El Niño - Southern Oscillation, with very strong intensity. The Southern Brazil presented greater conditions of atmospheric instability, with frequent passages of frontal systems and formation of extratropical cyclones, interfering in the sea conditions. In view of the above, this study aimed to evaluate the atmospheric conditions during rough sea events in the South and Southeast of Brazil during 2015/2016 El Niño, through information presented in the Warnings of Bad Weather, issued by the Hydrographic Center of the Brazilian Navy. Through these warnings and ERA-Interim reanalysis data, we analyzed the distributions by sea area, by month and by season of the year, as well as the analysis of
\end{abstract}

Autor de correspondência: Jeferson Prietsch Machado, jefpmac@gmail.com. 
synoptic fields plotted on the surface for the 12 most prominent events. As a result, the autumn and winter months recorded the highest occurrences of rough sea in both areas during the 2015/2016 El Niño. In general, four atmospheric patterns favorable to rough sea events were identified, due to the action of extratropical cyclones and the performance of post-frontal high pressure systems.

Keywords: El Niño, rough sea, atmospheric systems.

\section{Introdução}

Os sistemas meteorológicos que ocasionam tempestades acompanhadas de ventos fortes, como frentes frias e ciclones extratropicais, subtropicais e tropicais, muitas vezes interferem na condição de agitação do mar. Por mais que, geralmente, esses sistemas se formem em regiões sobre o oceano afastadas da costa, eles favorecem a agitação marítima e a propagação de ondas até a região costeira (Pond e Pickard, 1983). Como consequência, o nível do mar pode se elevar causando inundações na costa. Além disso, regiões costeiras com baixo relevo e densamente povoadas podem vir a sofrer desastres na presença de anomalias oceânicas (Campos et al., 2010; Candella e Souza, 2013). É importante destacar que, sendo o Brasil um território que apresenta um extenso litoral e, principalmente, pelo litoral Sul e do Sudeste estarem sob a influência desses sistemas meteorológicos, a condição de mar agitado ocorre com certa frequência. Além disso, atividades que incluem desde embarcações menores de pesca até grandes navios que necessitam realizar carregamentos e descarregamentos em portos, também são afetados em função da agitação marítima, causando prejuízos à economia, além do risco à tripulação.

De acordo com Bitencourt et al. (2002), pode-se conceituar o fenômeno ressaca como o aumento do nível do mar provocado pela elevação da maré astronômica e/ou maré meteorológica, acompanhado de ondas com amplitude maior que o normal. Os autores também destacam que o aumento do nível do mar ocorre principalmente pela maré meteorológica, que provoca o "empilhamento" de água na costa, devido à força do vento na superfície do mar.

Segundo Pugh (1987), a definição de maré meteorológica é a diferença entre a maré observada e a maré astronômica prevista, tendo como principais causas as variações de pressão atmosféricas e a transferência de momento que ocorre entre a atmosfera e a superfície oceânica através da tensão de cisalhamento (ou atrito) existente entre o fluido e a superfície. Sendo assim, a maré meteorológica junto com a maré astronômica é responsável pelo aumento ou pela diminuição do nível do mar, sendo que a primeira deve ser sempre relacionada com as observações registradas pela segunda em um determinado local (Marone e Camargo, 1994).

Vale ressaltar a importância da direção do vento durante eventos de ressaca, através do fenômeno conhecido como transporte de Ekman. Conforme Stewart (2005), a componente do vento paralela à costa terá uma resultante téorica à esquerda do movimento no Hemisfério Sul, em função do efeito de rotação da Terra. Desta forma, o transporte de Ekman atua de forma a empilhar ou retirar água da costa, dependendo da direção do vento (Bertin, 2016).

No Brasil, há alguns estudos voltados para eventos de ressaca. Por exemplo, Campos et al. (2010) caracterizaram os eventos extremos de nível do mar para SantosSP e concluíram que os meses de outono e inverno apresentaram a maior ocorrência de extremos positivos (ressaca). Neste contexto, Krueger (2011) analisou os parâmetros meteorológicos e oceanográficos dos eventos de ressaca ocorridos no litoral de Santa Catarina, entre janeiro de 2001 e dezembro de 2010, verificando que o mês de maio registrou o maior número de eventos de ressaca por se tratar do período de maior ciclogênese.

Outros estudos procuram focar apenas nas características particulares de determinados eventos de ressaca ocorridos no litoral Sul ou Sudeste do Brasil: Lima e Júnior (2000) realizaram uma caracterização sinótica e dinâmica da atmosfera para o período de evento de ressaca no Rio de Janeiro em abril de 1999, associando a ocorrência de ciclones extratropicais no sul do oceano Atlântico Sul com a intensa atividade de ondas que se propagam até a região costeira do Rio de Janeiro. Bitencourt et al. (2002) analisaram a situação atmosférica responsável pela ocorrência de dois casos de ressaca na costa da região Sul do Brasil durante o verão de 2002, associando os eventos com a configuração de ciclones extratropicais, além de verificarem que há proporcionalidade entre a intensidade do ciclone e a duração e extensão territorial dos eventos de ressaca. Candella e Souza (2013) investigaram o desenvolvimento da agitação marítima que atingiu o litoral sul e sudeste do Brasil durante o mês de maio de 2011 e as forçantes meteorológicas geradoras dessa agitação, associando ventos fortes e agitação marítima do litoral de Santa Catarina até o Rio de Janeiro com a configuração de um ciclone subtropical gerado abaixo de $30^{\circ} \mathrm{S}$ de latitude. Parise et al. (2009) determinaram a partir de dados de reanálise, as trajetórias dos ciclones extratropicais responsáveis por ocasionar eventos de marés meteorológicas intensas na praia do Cassino e associaram com eventos de erosão.

Os anos de 2015 e 2016 foram caracterizados pela ocorrência da fase positiva do fenômeno El Niño-Oscilação Sul (ENOS), denominada de El Niño, quando foram observadas anomalias positivas de temperatura da superfície do mar (TSM) na região do Pacífico Equatorial. De acordo com o Golden Gate Weather Service, este fenômeno foi classificado como "muito forte", apresentando anomalias de TSM superiores a $2{ }^{\circ} \mathrm{C}$ durante 2015 e 2016. Como consequência e corroborando os resultados de 
Fedorova e Carvalho (2000) e Silva e Ambrizzi (2010), o Sul do Brasil apresentou maiores condições de instabilidade atmosférica, com frequentes passagens de sistemas frontais e formação de ciclones extratropicais, interferindo nas condições de mar do litoral Sul e do Sudeste do Brasil.

Quando ocorrem períodos de El Niño, aumentam as condições de maior instabilidade atmosférica e ciclogênese nas regiões Sul e Sudeste do Brasil, interferindo nas condições do mar em suas respectivas áreas costeiras. Além disso, há uma intensificação do jato subtropical em função da intensificação da célula de Hadley, induzindo a um aumento do transporte de momento em direção aos polos na alta troposfera (Bjerknes, 1966; Chen et al., 1996; Grimm et al., 1998; Grimm e Ambrizzi, 2009). Segundo Reboita et al. (2015), para o Hemisfério Sul não existe diferença significativa no número de ciclogêneses em anos de El Niño, quando comparado a anos neutros e de La Niña, porém ocorre uma mudança na região de preferência de ocorrência destes sistemas, de modo que, em anos de El Niño, há aumento da ocorrência de ciclones entre $30^{\circ}$ e $60^{\circ} \mathrm{S}$ e diminuição entre $60^{\circ}$ e $70^{\circ} \mathrm{S}$. Ao explicar este fenômeno, Fogt et al. (2011), evidenciam a influência do Modo Anular Sul (SAM) sobre o posicionamento das áreas ciclogenéticas no hemisfério austral, uma vez que, em anos de El Niño, verifica-se a ocorrência da fase negativa do SAM, expandindo os jatos em direção a menores latitudes e, assim, confinando as regiões ciclogenéticas mais a norte. Partindo para uma escala mais regional, os estudos de Silva e Ambrizzi (2010) mostraram que em anos de El Niño fortes, há um pequeno aumento na densidade de ciclones extratropicais sobre o setor sudeste da América do Sul, cuja pressão central desses sistemas é mais profunda do que nos demais anos.

Devido aos riscos e às consequências que o fenômeno de ressaca pode trazer às atividades humanas e econômicas e, também, à escassez de estudos que explorem esse assunto, torna-se bastante relevante analisar, compreender e caracterizar o comportamento da atmosfera durante a ocorrência desses eventos. Também, devido ao fato do Brasil possuir um território com uma grande extensão litorânea, grande parte do país está exposto às condições de tempo associadas à passagem de frentes frias e à atuação de ciclones extratropicais e subtropicais, favorecendo condições de mar agitado com certa frequência, principalmente no litoral das regiões Sul e Sudeste.

Segundo Bitencourt et al. (2002) e Lima e Júnior (2000), o perigo que tripulantes, embarcações e a população que habita as regiões costeiras são submetidos a condições adversas do mar e os inúmeros prejuízos socioeconômicos contabilizados devido a ocorrência de ressaca na região sudeste do Brasil, principal polo industrial e econômico do país, torna o estudo deste fenômeno de maior importância, de modo a compreender melhor os processos físicos que provocam a agitação marítima. Por fim, há ainda o fato de haver a escassez de estudos e de dados que explorem esse assunto, requerendo mais pesquisas na área a fim de analisar, compreender e caracterizar o comportamento da atmosfera durante a ocorrência de ressaca, principalmente em períodos de El Niño que favorecem condições de maior instabilidade atmosférica e ciclogênese nas regiões Sul e Sudeste do Brasil, interferindo nas condições do mar em suas respectivas áreas costeiras.

Com base nos resultados dos estudos a respeito do fenômeno de ressaca, é possível aprimorar os prognósticos a respeito deste fenômeno, pois com melhores detalhamentos dos processos físicos que geram a agitação do mar e dados referentes a estudos passados, pode-se elucidar as ocorrências futuras (Candella, 1997; Innocentini e Caetano Neto, 1996). Recentemente, surgiu a primeira reanálise voltada para eventos de ressaca e níveis extremos do mar, denominada de Global Tide and Surge Reanalysss (GTSR), baseada em um modelo hidrodinâmico que cobre as regiões costeiras de todos os continentes (Muis et al., 2016). Entretanto, os autores destacam que ainda existe limitação com relação à forçante meteorológica.

Diante do exposto, o objetivo geral do presente trabalho é avaliar as condições atmosféricas durante eventos de ressaca no litoral Sul e do Sudeste do Brasil durante o El Niño 2015/2016, o qual foi considerando como muito forte e favoreceu a condições mais instáveis na região de estudo.

O artigo está organizado do seguinte modo: A seção 2 mostra uma descrição dos dados utilizados e a metodologia empregada (determinação dos eventos de ressaca). A seção 3 mostra a distribuição de frequência dos eventos de ressaca, bem como a análise sinótica para os casos selecionados durante o El Niño 2015/2016. Finalmente, as considerações finais são abordadas na seção 4.

\section{Materiais e Métodos}

Diferentemente da grande maioria dos trabalhos que abordam o tema ressaca e que utiliza da divulgação de notícias em diferentes meios de comunicação como fonte de dados, no estudo em questão foi desenvolvida uma nova metodologia, a qual se baseia nas informações que constituem os Avisos de Mau Tempo, emitidos pelo Centro de Hidrografia da Marinha do Brasil (CHM). Esses avisos funcionam como alertas de condições de tempo adversas, sendo emitidos de forma imediata e, depois, incluídos no METEOMARINHA e em outros boletins de previsão. Sua emissão ocorre quando uma ou mais condições pré-estabelecidas de tempo ou mar sejam previstas, de modo que, para o presente estudo, a condição de "ressaca, com ondas de 2,5 metros ou mais atingindo a costa com direção favorável" foi a única considerada de interesse. Deste modo, adotou-se como fonte de dados todos os Avisos de Mau Tempo do CHM que continham a mensagem "Aviso de Ressaca". 
Em função da disponibilidade dos Avisos de Mau Tempo do CHM ser de setembro de 2016 a julho de 2017, optou-se por realizar a distribuição de frequência e a climatologia dos eventos de ressaca para o período de janeiro de 2007 a dezembro de 2016. Logo após, foram utilizados os avisos de ressaca somente nos meses em que foi registrada a ocorrência da fase quente do ENOS, ou seja, todos os meses com a atuação do fenômeno El Niño durante 2015 e 2016. Segundo dados disponibilizados pelo Climate Predicition Center, do National Weather Service (NOAA), no que diz respeito ao foco deste estudo, foram registrados, segundo o índice ONI (Oceanic Niño Index), eventos quentes do ENOS desde o mês de janeiro de 2015 até o mês de junho de 2016. De acordo com Pereira et al. (2017), o ONI é um índice que calcula a média móvel de três meses das anomalias de TSM na região de Niño $3.4\left(5^{\circ} \mathrm{N}-5^{\circ} \mathrm{S}\right.$, $120^{\circ}-170^{\circ} \mathrm{O}$ ). Quando cinco valores consecutivos forem iguais ou acima (abaixo) do valor $0,5(-0,5)$ há ocorrência de El Niño (La Niña). Vale ressaltar que este índice variou entre $+0,6 \mathrm{e}+2.6$ entre o trimestre outubronovembro-dezembro (OND) de 2014 ao trimestre abrilmaio-junho (AMJ) de 2016, sendo classificado como "muito forte".
A área de estudo compreende a faixa litorânea das regiões Sul e Sudeste do Brasil, bem como a porção oeste do Atlântico Sul. Para a delimitação dessa área, tomou-se como critério a divisão realizada pelo $\mathrm{CHM}$ em áreas marítimas de previsão de tempo sob responsabilidade do Brasil, adotando como região de interesse as áreas ALFA (A), correspondente à faixa costeira desde o Arroio Chuí (RS) até o Cabo de Santa Marta (SC), e CHARLIE (C), estendendo-se desde a faixa costeira do Cabo de Santa Marta (SC) até Cabo Frio (RJ), destacadas na Fig. 1.

A extensão de cada uma das duas áreas, bem como as coordenadas geográficas (sendo $\phi$ a latitude e $\lambda$ a longitude) dos pontos de monitoramento nelas presentes, são informadas de acordo com as Tabelas 1 e 2.

$\mathrm{Na}$ tentativa de se excluir a possibilidade de serem contabilizadas duas ou mais ocorrências de ressaca causadas pelo mesmo sistema meteorológico atuante, considerou-se como mesmo evento de ressaca todos os Avisos de Mau Tempo com data de validade igual ou com, no máximo, dois dias consecutivos de diferença, considerações válidas para cada uma das áreas marítimas em estudo.

Com base nas informações disponíveis para o trabalho e nas considerações realizadas, foi feita, primeiramente, a contabilização dos eventos separadamente para a área

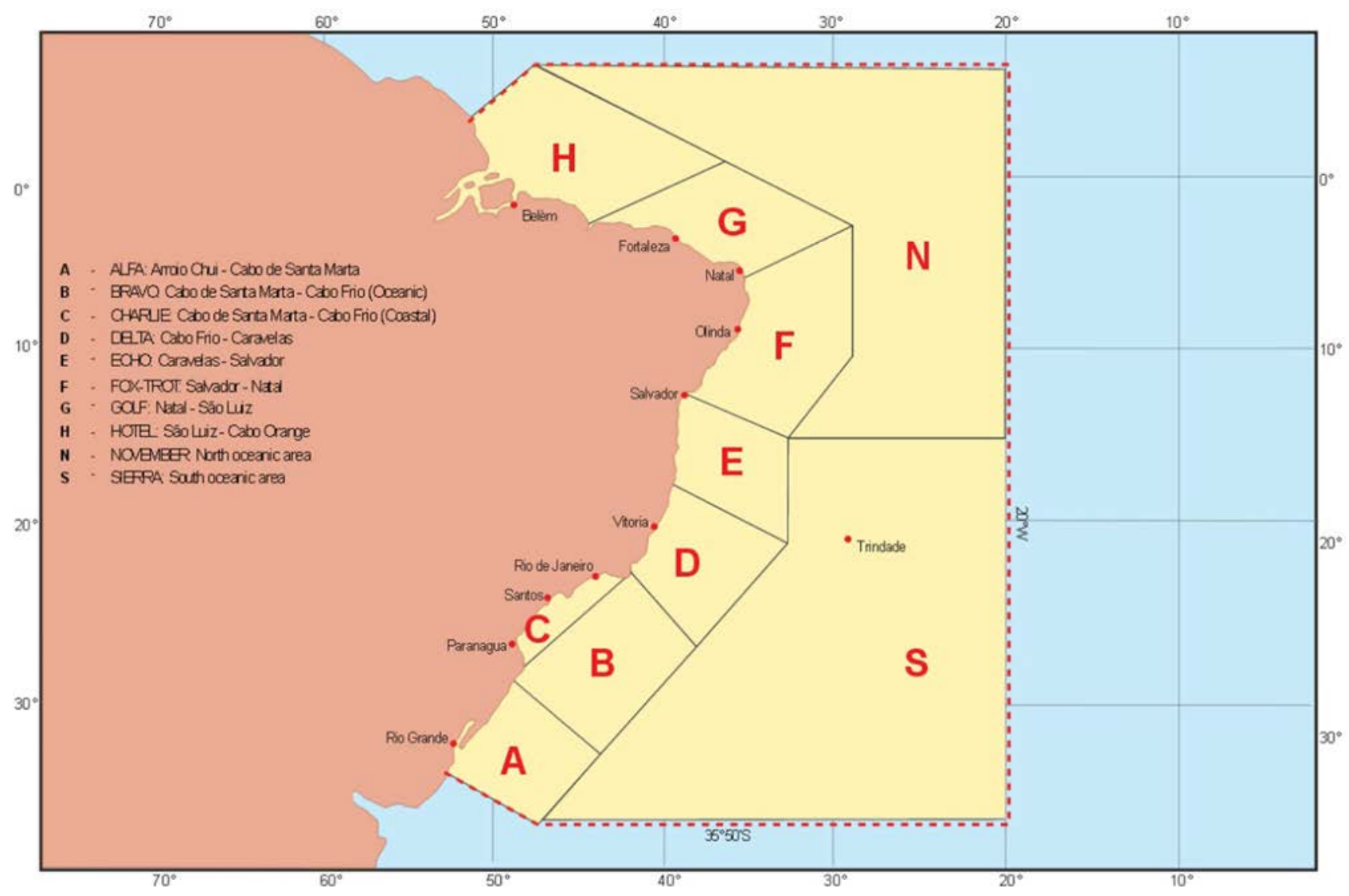

Figura 1 - Áreas marítimas de previsão de tempo sob responsabilidade do Brasil. Disponível em: https://www.marinha.mil.br/chm/dados-do-smm-avisosde-mau-tempo/avisos-de-mau-tempo. 
Tabela 1 - Área marítima ALFA: limites e pontos de monitoramento.

\begin{tabular}{lcc}
\hline \multicolumn{2}{l}{ ALFA (A): Arroio Chuí (RS) - Cabo de Santa Marta (SC) } \\
\hline Pontos & $\phi$ & $\lambda$ \\
\hline 1 & $33^{\circ} 44^{\prime} \mathrm{S}$ & $53^{\circ} 22^{\prime} \mathrm{W}$ \\
2 & $36^{\circ} 00^{\prime} \mathrm{S}$ & $48^{\circ} 00^{\prime} \mathrm{W}$ \\
3 & $31^{\circ} 00^{\prime} \mathrm{S}$ & $43^{\circ} 00^{\prime} \mathrm{W}$ \\
4 & $28^{\circ} 36^{\prime} \mathrm{S}$ & $48^{\circ} 49^{\prime} \mathrm{W}$ \\
\hline \multicolumn{2}{l}{ Fonte: Centro de Hidrografia da Marinha do Brasil. }
\end{tabular}

Tabela 2 - Área marítima CHARLIE: limites e pontos de monitoramento.

\begin{tabular}{lcc}
\hline \multicolumn{2}{c}{ CHARLIE (C): Cabo de Santa Marta (SC) - Cabo Frio (RJ) (Costeira) } \\
\hline Pontos & $\phi$ & $\lambda$ \\
\hline 1 & $28^{\circ} 36^{\prime} \mathrm{S}$ & $48^{\circ} 49^{\prime} \mathrm{W}$ \\
2 & $23^{\circ} 01^{\prime} \mathrm{S}$ & $42^{\circ} 00^{\prime} \mathrm{W}$
\end{tabular}

Fonte: Centro de Hidrografia da Marinha do Brasil.

A e para a área C. Em seguida, realizou-se a distribuição da frequência dos eventos de ressaca por área e, também, a distribuição mensal e sazonal. Para a distribuição sazonal, considerou-se primavera (setembro, outubro e novembro), verão (dezembro, janeiro e fevereiro), outono (março, abril e maio) e inverno (junho, julho e agosto).

A partir de então, foram selecionadas todas as ocorrências de ressaca simultâneas para as duas áreas que ocorreram durante o El Niño 2015/2016, partindo do pressuposto de que ocorrências simultâneas associam-se com o mesmo sistema meteorológico atuante sobre ambas as áreas. Dentre todas as ocorrências simultâneas de ressaca registradas, foram selecionados 12 casos em particular para as análises sinóticas (Tabela 3). Essa última seleção considerou como principal critério a altura das ondas, sendo que, esses 12 casos selecionados compreendem as 12 ocorrências com maiores alturas de ondas registradas pelos Avisos de Mau Tempo.

$\mathrm{O}$ estudo de cada um dos 12 casos foi realizado através da análise de campos gerados a partir da reanálise do ERA-Interim (Dee et al., 2011), com resolução espacial de $0,75^{\circ} \times 0,75^{\circ}$. Foram utilizados os seguintes dados: vento zonal e meridional (a 10 metros da superfície) e pressão ao nível médio do mar (PNMM) para os horários das 0, 6, 12 e 18 Z. Além disso, para auxiliar na caracterização dos eventos de ressaca, foram utilizados dados de análise do modelo de onda WAVEWATCH III com resolução espacial de $0,5^{\circ}$ x $0,5^{\circ}$ (Tolman, 2014). As seguintes variáveis foram utilizadas: altura significativa, direção e período médio da onda disponibilizados de três em três horas.

O tempo de duração $(T)$ de cada caso constitui na diferença, em dias, entre a data de validade do Aviso de Mau Tempo $\left(D_{v}\right)$ e a data inicial do evento $\left(D_{i}\right)$, segundo mesmo aviso (Eq. (1)). Para gerar os campos sinóticos, fez-se a média dos dados da reanálise do ERA-Interim e
Tabela 3 - Informações sobre os eventos simultâneos $(A+C)$ de ressaca: duração do evento, direção e altura das ondas.

\begin{tabular}{lccc}
\hline Caso & Evento & \multicolumn{2}{c}{ Onda } \\
\cline { 3 - 4 } & Duração & Direção & Altura (m) \\
\hline 1 & $29 / 04 / 2015$ a $01 / 05 / 2015$ & SE/SW & $2,5-3,0$ \\
2 & $13 / 05 / 2015$ a 15/05/2015 & SE & $2,5-3,0$ \\
3 & $18 / 06 / 2015$ a 20/06/2015 & S/SE/SW & $2,5-4,0$ \\
4 & $23 / 06 / 2015$ a $26 / 06 / 2015$ & S/SW & $2,5-3,0$ \\
5 & $21 / 07 / 2015$ a 23/07/2015 & E/SE/SW & $2,5-3,0$ \\
6 & $21 / 08 / 2015$ a 22/08/2015 & S/SE & $2,5-3,0$ \\
7 & $01 / 09 / 2015$ a 03/09/2015 & S/SE/SW & $2,5-3,5$ \\
8 & $17 / 10 / 2015$ a 19/10/2015 & S/SE/SW & $2,5-3,0$ \\
9 & $03 / 03 / 2016$ a 06/03/2016 & E/SE & $2,5-3,0$ \\
10 & $26 / 03 / 2016$ a 27/03/2016 & E/SE & $2,5-3,5$ \\
11 & $22 / 05 / 2016$ a 26/05/2016 & S/SE/SW & $2,5-3,0$ \\
12 & $10 / 06 / 2016$ a 14/06/2016 & S/SW & $2,5-4,0$ \\
\hline
\end{tabular}

do modelo de onda ao longo do tempo de duração de cada caso (Tabela 3).

$$
T=D_{v}-D_{i}
$$

\section{Resultados e Discussão}

\subsection{Distribuição de frequência}

A Fig. 2a mostra a distribuição anual dos eventos de ressaca entre 2007 e 2016 para as áreas A e C, onde uma observa-se uma variabilidade no número de casos para cada área e de ano para ano. Entretanto, a média anual é de 24 eventos de ressaca para ambas as áreas. Por outro lado, fica evidente que, dentre os dez anos de informações, os anos de 2015 e 2016 foram os que mais ocorreram ressacas de acordo com os Avisos de Mau Tempo do CHM, sendo a maior ocorrência na área $\mathrm{A}$, indicando a influência do El Niño 2015/2016 de intensidade muito forte. Vale ressaltar que entre os anos de 2006 a 2014 ocorreram 3 eventos de El Niño (2 com fraca intensidade e 1 moderado) e 4 eventos de La Niña, sendo o ocorrido entre 2010 e 2011 de forte intensidade. Neste contexto, nota-se que o ano de 2010 foi o que mostrou o menor número de eventos de ressaca na área A. A partir da distribuição mensal das ocorrências de ressaca (Fig. 2b) é possível observar que elas ocorrerem durante todo os meses do ano nas áreas A e $\mathrm{C}$, principalmente entre maio e setembro, período em que os ciclones extratropicais e os sistemas frontais ocorrerem com maior frequência (Reboita et al., 2015; Gan e Seluchi, 2009; Cavalcanti e Kousky, 2009, Gan e Rao, 1991), interferindo nas condições de tempo e de mar nos litorais sul e sudeste do Brasil. Sazonalmente, os meses de inverno (JJA) são os que apresentam o maior número de eventos em ambas as áreas.

Considerando a distribuição da frequência total dos eventos de ressaca contabilizados através dos Avisos de 
a) Ressacas entre 2007 e 2016

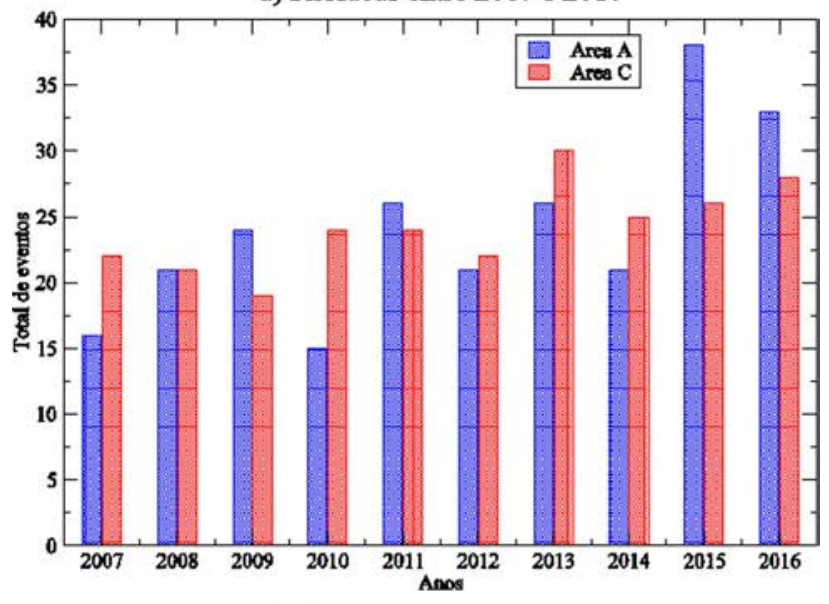

b) Freq. mensal de ressacas

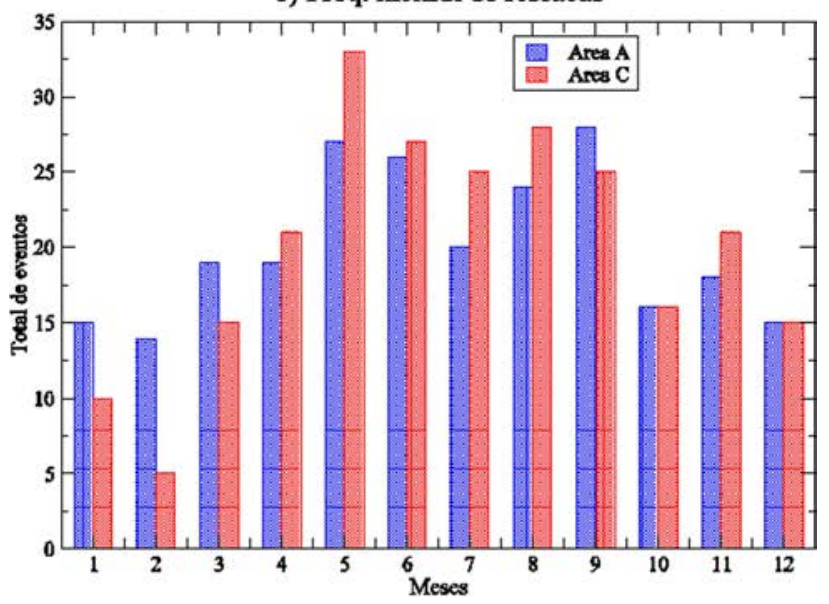

c) Freq. mensal de ressacas- El Nino 2015/2016

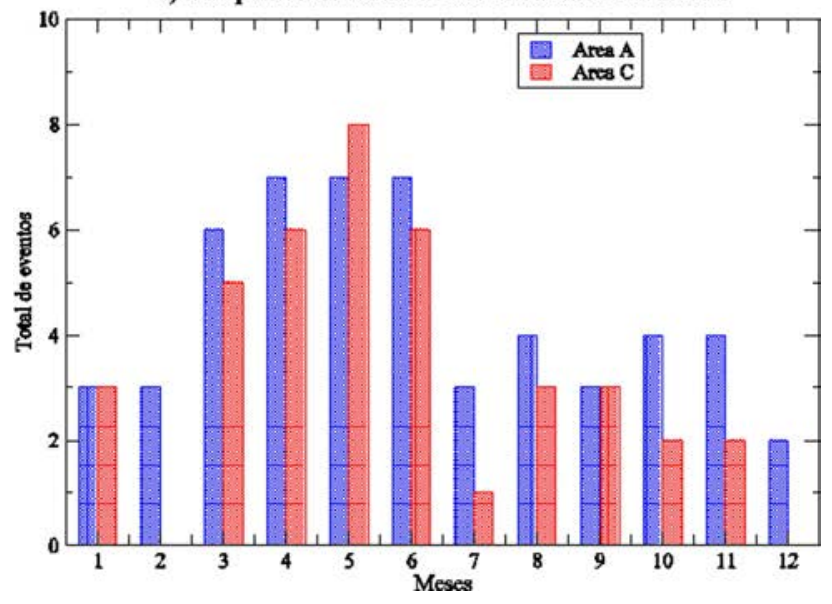

Figura 2 - Frequência de eventos de ressaca por área. (a) Frequência anual entre 2007 e 2016; (b) Frequência mensal entre 2007 e 2016 e; (c) Frequência mensal durante o El Niño 2015/2016.

Mau Tempo do CHM ao longo do período do El Niño 2015/2016, a área A registrou 53 episódios do fenômeno, enquanto que a área $\mathrm{C}$ registrou 39 casos. A diferença no número de casos por área se dá, possivelmente, pela loca- lização de cada uma das áreas: a área A encontra-se em latitudes mais elevadas, coincidindo com uma região ciclogenética da América do Sul (Reboita et al, 2015), bem como com uma área de atuação dos sistemas de alta pressão pós-frontais, ou seja, sofre forte influência de sistemas meteorológicos favoráveis à ocorrência de ressaca. $\mathrm{A}$ área $\mathrm{C}$, no entendo, localiza-se em latitudes mais baixas, mais a norte das regiões ciclogenéticas do continente sulamericano, sendo menos influenciada diretamente por esses sistemas.

A distribuição mensal por área desses eventos de ressaca ao longo do período do El Niño 2015/2016 (Fig. 2c) apontou que, mesmo havendo diferença na quantidade de episódios do fenômeno, os meses de maior ocorrência de ressaca foram os mesmo para ambas as áreas: a área A registrou 7 casos nos meses de abril, maio e junho e 6 casos em março; a área $C$ registrou 8 casos em maio, 7 casos em abril e junho e 6 casos em março. Esse resultado está de acordo com o trabalho de Campos et al. (2010) e Krueger (2011), registrando mais eventos de ressaca nas regiões Sul e Sudeste do Brasil durante os meses de outono e de inverno.

Para o ano de 2015, foram realizadas distribuições mensais e sazonais da frequência dos eventos de ressaca em ambas as áreas, uma vez que, para esse período, todos os meses do ano foram considerados. Já para o ano de 2016, foi realizada apenas a distribuição mensal para cada área, pois, pelo fato do índice ONI considerar condições de El Niño 2015/2016 somente até junho de 2016, não houve dados referentes a todos os meses do ano, não sendo possível realizar uma análise sazonal da frequência de eventos.

Em 2015, a área A registrou maior número de casos de ressaca (4 eventos) nos meses de abril, junho, agosto, outubro e novembro, ao passo que a área $\mathrm{C}$ registrou maior frequência desses casos nos meses de maio e junho. Agrupando os eventos registrados em 2015 em trimestres que correspondem às estações do ano, a distribuição mensal de frequência leva à distribuição sazonal, registrando para ambas as áreas maior frequência de ressaca durante o outono, inverno e a primavera. Por outro lado, o maior número de ressacas registradas em 2015 em relação aos anos anteriores, pode ser explicado, segundo os estudos de Pereira et al. (2017), pela presença de anomalias negativas de altura geopotencial no sudeste do continente sul-americano e no oceano Atlântico durante a primavera de 2015, modulando os jatos de baixos níveis (JBN) do modo a transportarem umidade dos trópicos para os subtrópicos, contribuindo para maior frequência de ciclones nas latitudes subtropicais do oceano Atlântico.

Considerando somente os 12 casos selecionados para a obtenção do padrão sinótico (Tabela 3), fez-se uma distribuição sazonal da frequência dos eventos de ressaca, obtendo 5 casos ocorridos no período de outono $(41,7 \%$ dos casos), 5 casos ocorridos durante o inverno (41,7\% dos casos), 2 casos nos meses de primavera $(16,6 \%)$ e 
nenhum caso nos meses de verão. Esse resultado indica que, mesmo sob condições de El Niño muito forte, o outono e o inverno continuam sendo as estações do ano preferenciais para ocorrência de ressaca no litoral Sul e Sudeste do Brasil, independentemente do padrão atmosférico associado à essas ocorrências. Fez-se, também uma distribuição da frequência dos eventos de ressaca em relação às fases lunares em que se encontravam cada um desses casos. Como resultado, obteve-se 6 casos ocorridos durante a Lua Nova (50\% dos casos), 3 casos ocorridos durante a Lua Cheia ( $25 \%$ dos casos), 2 casos ocorridos durante a Lua Minguante (16,7\%) e, apenas 1 caso ocorrido durante a Lua Crescente (8,3\%). Esse resultado indica que, em $75 \%$ das ocorrências de ressaca (Tabela 3), o fenômeno estava sob influência da Maré de Sizígia que, por sua vez, favoreceu a agitação marítima e contribuiu para o aumento do nível do mar. Os $25 \%$ restantes, no entanto, encontravam-se sob influência da Maré de Quadratura, não havendo o favorecimento do aumento do nível do mar por forçantes astronômicas.É importante destacar que os quatro casos analisados que registraram as maiores alturas de ondas (casos 3, 7, 10 e 12) ocorreram em períodos de outono (casos 3, 10 e 12) e inverno (caso 7) e sob a influência da Maré de Sizígia.

\subsection{Análise dos eventos de ressaca}

Através da análise dos campos sinóticos plotados e de acordo com os casos selecionados da Tabela 3, identificou-se quatro padrões atmosféricos favoráveis à ocorrência de ressacas no litoral do Sul e do Sudeste do Brasil. Desta forma, os 12 casos selecionados serão mostrados agrupados em cada padrão sinótico identificado.

\subsubsection{Padrão 1: Presença de ciclone extratropical entre $30^{\circ} \mathrm{Se}$ $40^{\circ} \mathrm{S}$}

O primeiro padrão que será mostrado engloba 3 eventos de ressaca ocorridos durante o El Niño 2015/2016 (casos 1, 2 e 6). De acordo com os avisos de mau tempo da marinha, os 3 casos apresentavam condição de ressaca nas regiões A e C, com ventos de sudoeste a sudeste e ondas com altura das ondas de $2,5 \mathrm{~m}$ a $3 \mathrm{~m}$, conforme informações da Tabela 3.

$\mathrm{Na}$ análise da Fig. 3 (a,b,c) notou-se pelo campo de pressão atmosférica ao nível médio do mar a atuação da Alta Subtropical do Atlântico Sul (ASAS) com seu centro, aproximadamente, entre $20^{\circ}$ e $40^{\circ} \mathrm{S}$ e $0^{\circ}$ de longitude. À sudoeste da ASAS, notou-se a atuação de um sistema de baixa pressão com centro entre $30^{\circ}$ e $40^{\circ} \mathrm{S}$, seguido por um outro sistema de alta pressão (na retaguarda do ciclone), este último atuando mais próximo ao Rio Grande do Sul, ao Uruguai e à Argentina para os 3 casos de ressaca. A configuração de um sistema de baixa pressão em superfície na porção oeste do Atlântico Sul seguido por um sistema de alta pressão gera as chamadas "pistas de vento", pois os escoamentos de ambos os sistemas con- (a) Pressoo ao Nivel Medio do Mar [hPo]

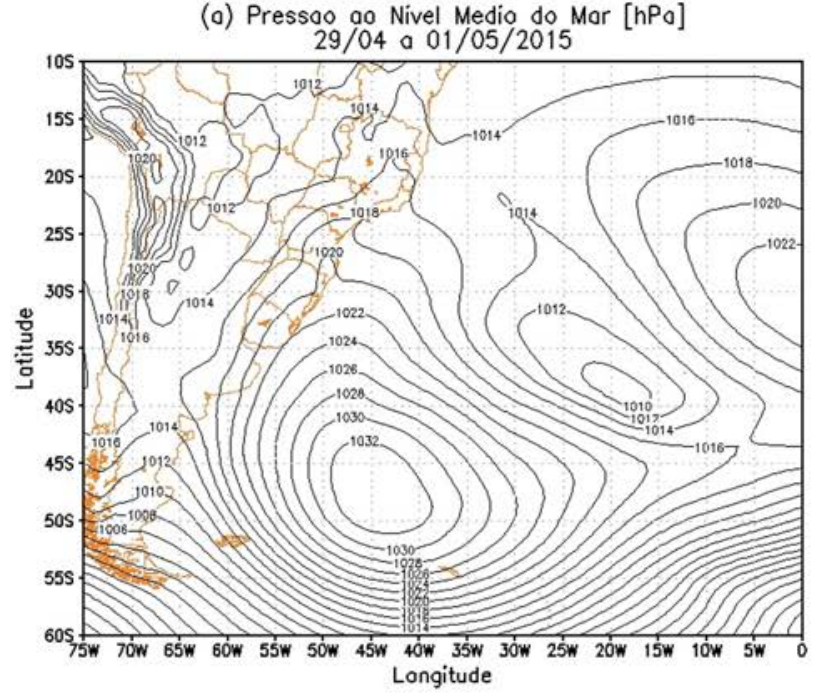

(b) Pressoo ao Nivel Medio do Mor [hPo]

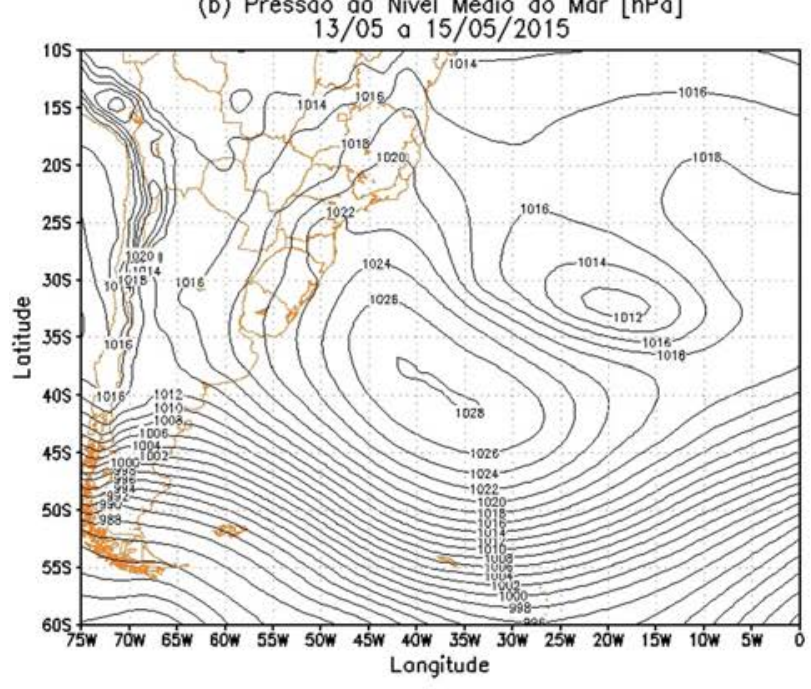

(c) Pressao ao Nivel Medio do Mar [hPo]

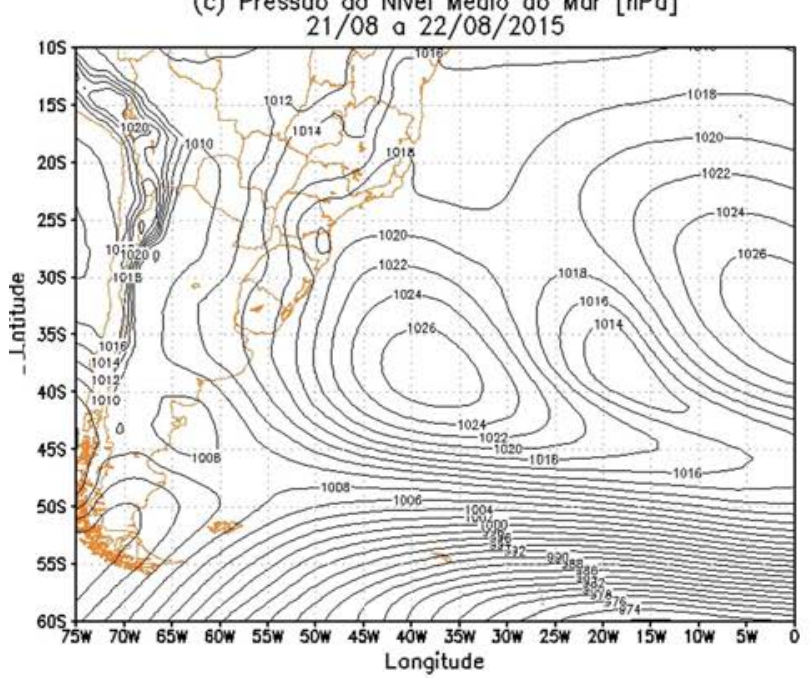

Figura 3 - Pressão ao nível médio do mar $(\mathrm{hPa})$ plotada a partir da reanálise do ERA-Interim para os casos 1 (a), 2 (b) e 6 (c). 
fluem sobre o oceano e se deslocam em direção ao continente, como é mostrado na Fig. 4 (a,b,c). Pela reanálise do Era-Interim, os ventos foram predominantes de sudeste a leste e velocidade média de aproximadamente $8 \mathrm{~m} / \mathrm{s}$ $(30 \mathrm{~km} / \mathrm{h})$ nas regiões mais próximas da costa para o período do evento nos 3 casos. O vento foi mais intenso justamente na região de formação das pistas de vento, em função do forte gradiente de pressão entre o ciclone e alta pressão na retaguarda. A interação entre o escoamento na baixa troposfera e as superfícies oceânicas devido à transferência de momento e de energia entre a atmosfera e o oceano resulta na agitação das águas marítimas, caracterizando as ondas. Para o desenvolvimento das ondas superficiais de gravidade, são necessárias três condições básicas para o vento em atrito com o mar: sua intensidade, sua duração e o espaço geográfico em que se encontra com direção praticamente constante ("pista de vento") (Candella e Souza, 2013). Uma relação entre os centros de baixa pressão em superfície e a agitação do mar foi encontrada por Bitencourt et al. (2002), sobre a qual o autor observa que quanto maior a intensidade do ciclone extratropical, maior será a extensão territorial atingida pela ressaca e maior será, também, o período de duração do fenômeno. De acordo com Parise et al. (2009), existem três trajetórias dos ciclones extratropicais que afetam, em particular, a costa do Rio Grande do Sul: Ciclogênese ao sul da Argentina com deslocamento para leste e trajetória entre $47.5^{\circ} \mathrm{S}$ e $57.5^{\circ} \mathrm{S}$; 2) Ciclogênese ao sul do Uruguai com deslocamento para leste e trajetória entre $35^{\circ} \mathrm{S}$ e $42.5^{\circ} \mathrm{S}$; 3) Ciclogênese ao sul do Uruguai com deslocamento para sudeste e trajetória entre $35^{\circ} \mathrm{S}$ e $57.5^{\circ} \mathrm{S}$. Além disso, os autores destacam que o padrão 2 favorece a condição de vento mais intenso e, consequentemente, a elevação do nível do mar.

Desta forma, entende-se que a configuração e a disposição de sistemas de baixa pressão (ciclone extratropical) e de alta pressão na retaguarda do ciclone formaram o padrão atmosférico responsável pela ocorrência deste evento de ressaca, através da geração das "pistas de vento" que, por sua vez, favoreceram o empilhamento de água sobre a costa Sul e Sudeste do Brasil. Isto pode ser observado pela análise do modelo de onda WAVEWATCH III (Fig. 5(a,b,c)) que informa a altura e direção da onda. Logo, os campos do modelo indicaram ondas com altura de aproximadamente $3 \mathrm{~m}$, principalmente na costa Sul e mais altas em regiões mais afastadas da costa. Além disso, a direção média da onda para o período foi de sul a leste nos 3 eventos. Vale ressaltar que pelo posicionamento do ciclone extratropical e a alta pressão na sua retaguarda influenciaram de forma mais significativa o litoral Sul do Brasil.

\subsubsection{Padrão 2: Alta pressão pós-frontal com centro entre o Litoral do Uruguai e da Argentina}

O segundo padrão atmosférico encontrado em eventos de ressaca durante o El NIño 2015/2016 foi observado

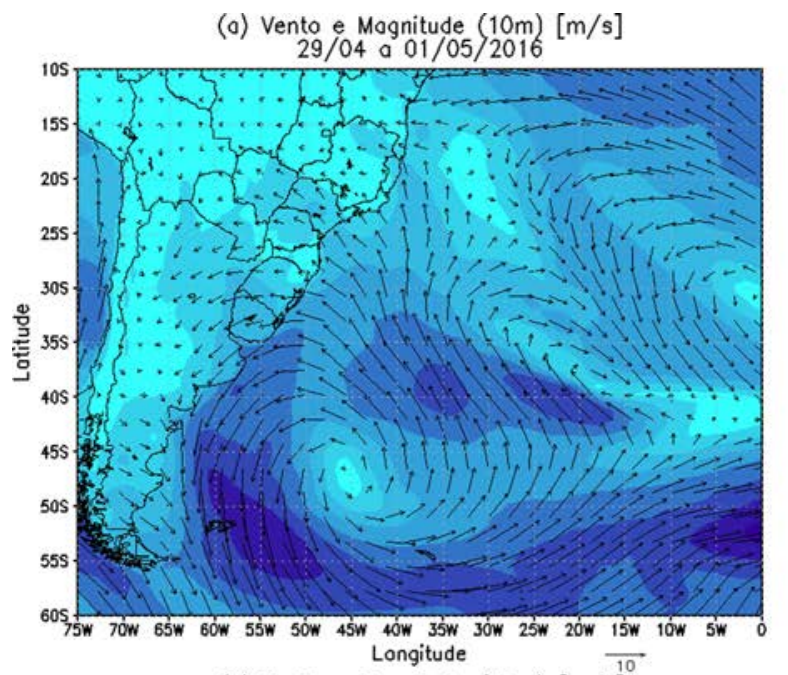

(b) Vento e Mognitude $(10 \mathrm{~m})[\mathrm{m} / \mathrm{s}]$

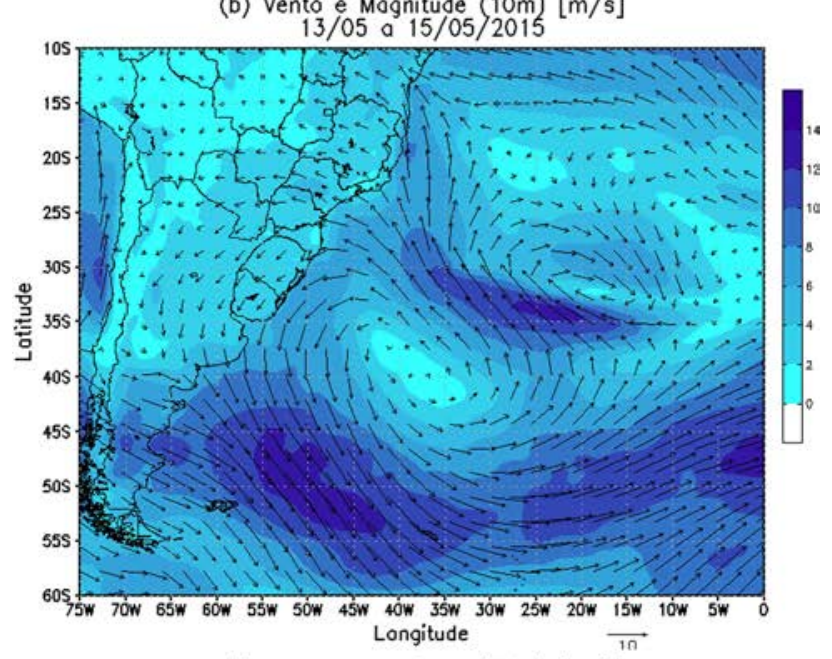

(c) Vento e Magnitude $(10 \mathrm{~m})[\mathrm{m} / \mathrm{s}]$ $21 / 08$ a $22 / 08 / 2015$

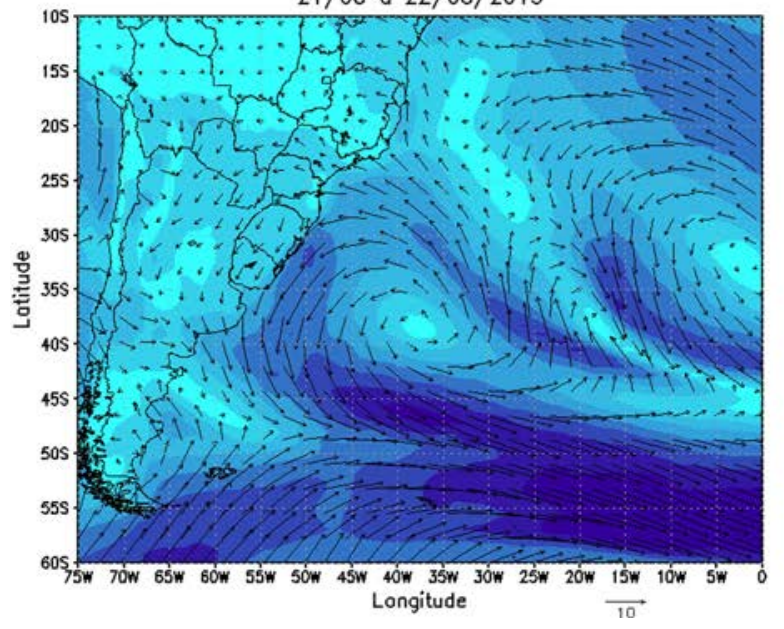

Figura 4 - Direção e magnitude do vento $(\mathrm{m} / \mathrm{s})$ plotados a partir da reanálise do ERA-Interim para os casos 1 (a), 2 (b) e 6 (c).

nos casos 3, 4, 5, 7, 8 e 9 (Tabela 3), o qual ocorreu com maior frequência dentre os 12 eventos selecionados. Através da Fig. 6 notou-se que o campo de pressão atmos- 
(a) Altura [m] e direcao da onda

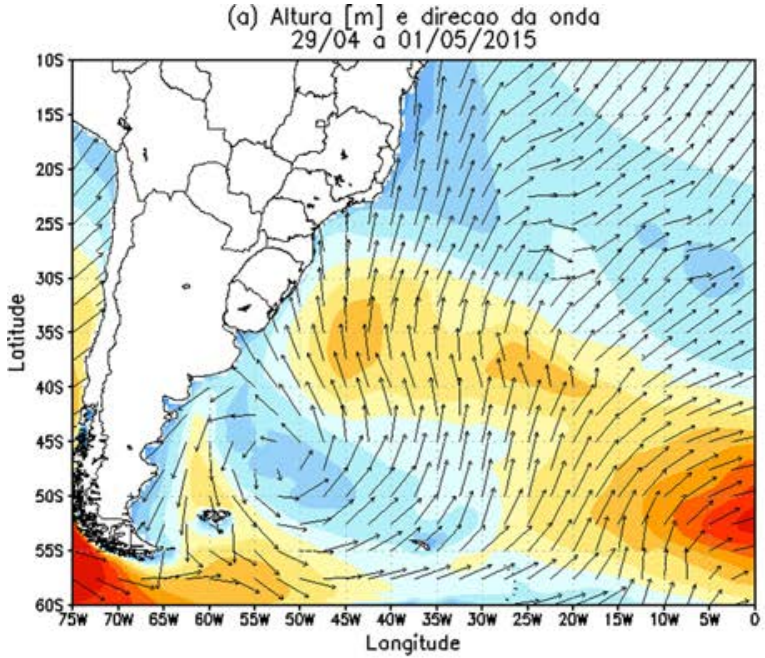

(b) Altura [m] e direcao da ondo

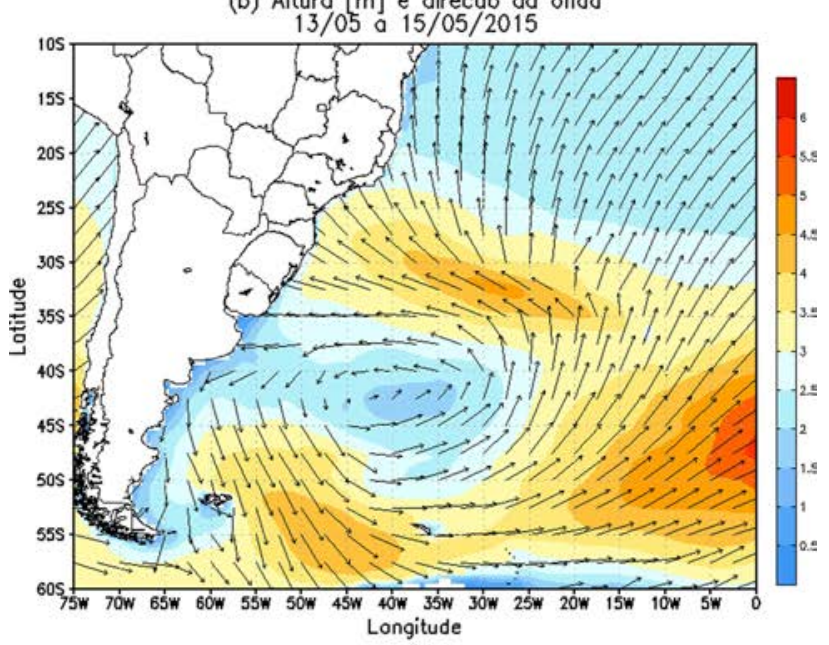

(c) Alturo [m] e direcao do ondo

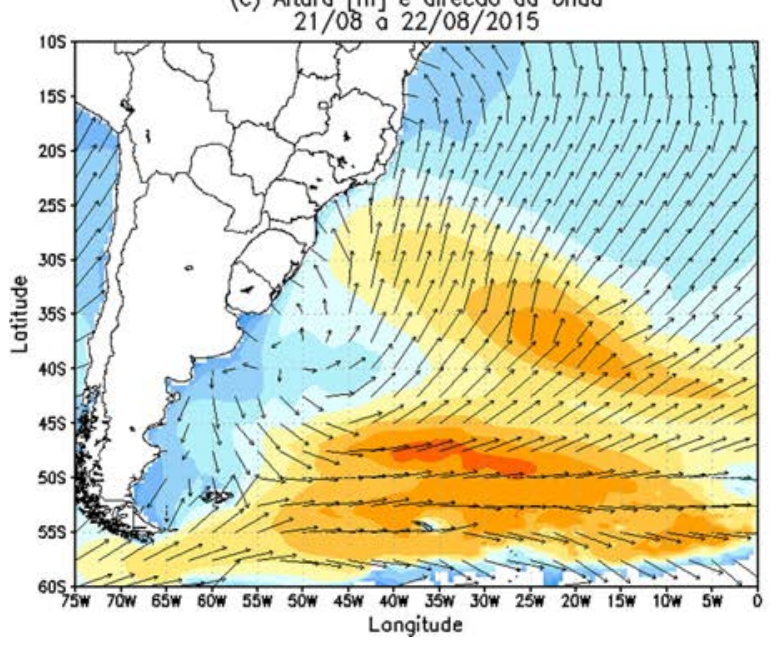

Figura 5 - Altura (m) e direção da onda plotados a partir do modelo WAVEWATCH III para os casos 1 (a), 2 (b) e 6 (c).

férica ao nível médio do mar evidenciou a atuação da ASAS com seu centro, aproximadamente, entre $20^{\circ}$ e $40^{\circ}$ $\mathrm{S}$ e $0^{\circ}$ de longitude. Próximo ao Sul do Brasil e com centro entre o Uruguai e a Argentina, havia outro sistema de alta pressão em superfície. Ao contrário dos casos do Padrão 1, não houve configuração de um sistema fechado de baixa pressão (ciclone extratropical) entre $30^{\circ}$ e $40^{\circ} \mathrm{S}$, mas a formação de um cavado, entre os dois sistemas de alta pressão, o que caracteriza um sistema frontal sobre o oceano para os 6 casos de ressaca. Nesta configuração, a baixa pressão associada à frente fria estava posicionada em altas latitudes do oceano Atlântico. Neste caso, o escoamento dos ventos que chegam até o litoral Sul e Sudeste do Brasil (Fig. 7) se deu pela influência do sistema de alta pressão em superfície, com centro próximo ao litoral do Uruguai e da Argentina, com ventos de S/SE moderados, principalmente no Litoral Sul do Brasil. Vale ressaltar que esta configuração foi semelhante para os 6 eventos analisados.

A influência do sistema de alta pressão pós-frontal sobre o Atlântico pode ser verificada na Fig. 8, através das análises de altura e direção da onda do modelo WAVEWATCH III para os 6 eventos que apresentaram essa configuração. De acordo com as informações do modelo, a altura das ondas foi de aproximadamente $3,5 \mathrm{~m}$, principalmente no litoral do Rio Grande do Sul e de Santa Catarina, com direção de sul/sudeste. Este padrão de altura e direção da onda favorece ao empilhamento de água sobre a costa Sul e Sudeste do Brasil, por meio de seu escoamento, majoritariamente, de quadrante sul. Neste caso, aplica-se o conceito do Transporte de Ekman, resultando no transporte de água a $90^{\circ}$ da direção do vetor vento, ou seja, houve transporte de água de leste para oeste (do oceano para a costa) (Ribeiro, 2003).

De um modo geral, para os 6 casos, entende-se que, não havendo a configuração e a disposição de sistemas de baixa e de alta pressão em superfície, não houve favorecimento para a formação das "pistas de vento". Neste caso, o padrão atmosférico responsável pela ocorrência do evento de ressaca, foi a atuação e a localização de um sistema de alta pressão pós-frontal em superfície com centro entre o Uruguai e Argentina que propiciaram o empilhamento de água sobre a costa Sul e Sudeste do Brasil.

\subsubsection{Padrão 3: Alta pressão pós-frontal com centro sobre o Uruguai}

O terceiro padrão identificado ocorreu em duas situações referentes aos 12 casos (Casos 11 e 12) e será mostrado a seguir. Através dos campos de pressão ao nível médio do mar gerados a partir da reanálise do Era-Interim (Fig. 9(a,b)), foi possível observar uma configuração semelhante a padrão 2. Logo, nestes 2 eventos de ressaca notou-se a passagem de uma frente fria (identificada pelo cavado entre os dois sistemas de alta pressão) e a alta pressão pós-frontal ficou posicionada mais sobre o continente, diferenciando-se do padrão anterior em que o sistema de alta pressão encontrava-se mais sobre o litoral. Isto 
(a) Pressoo ao Nivel Medio do Mor [hPo]

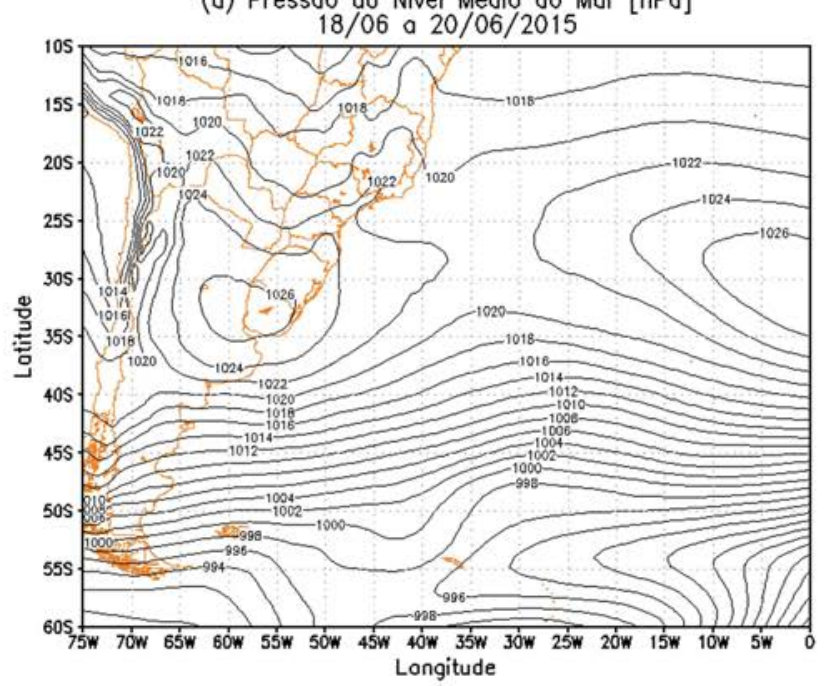

(c) Pressao ao Nivel Medio do Mar [hPa]

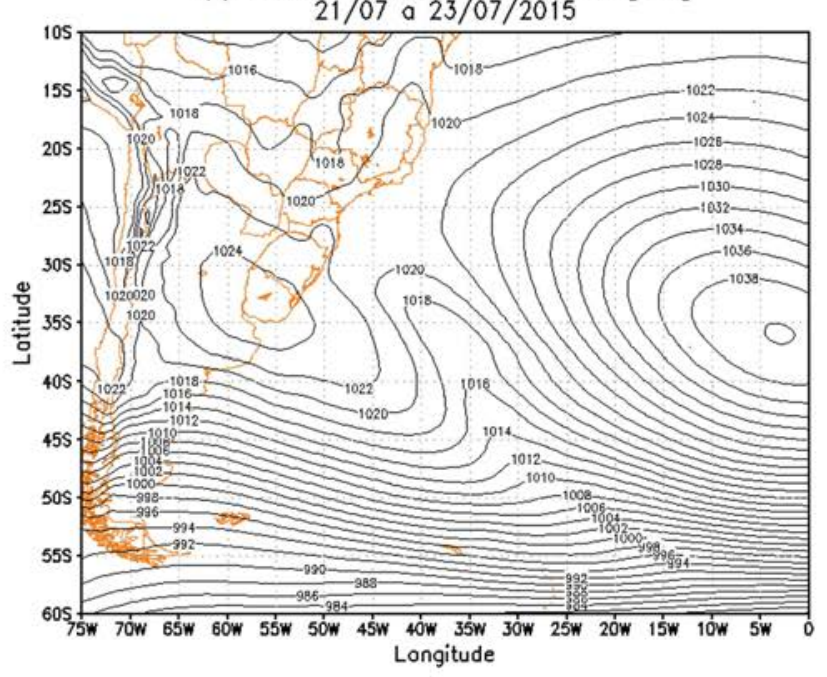

(e) Pressao ao Nivel Medio do Mar [hPa]

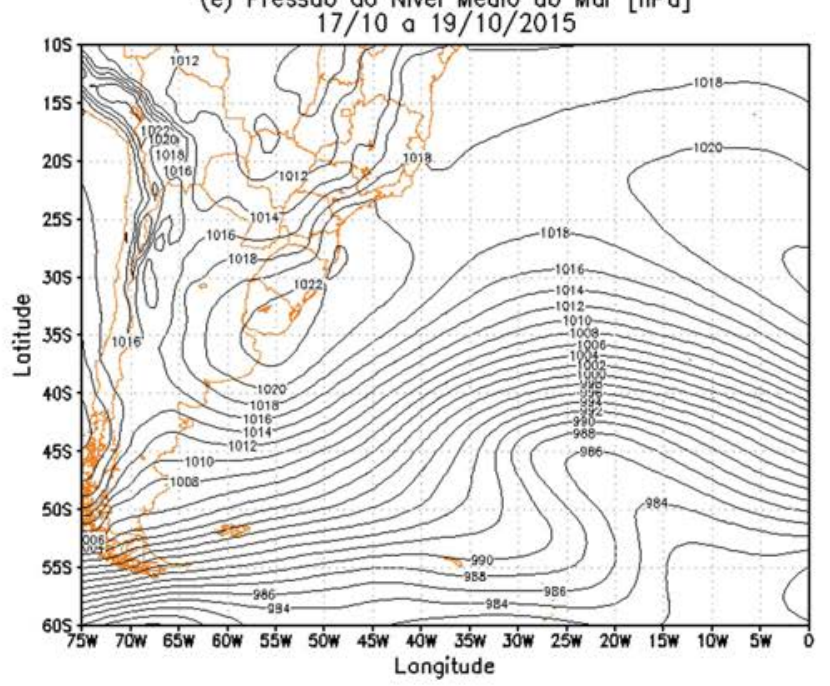

(b) Pressao ao Nivel Medio do Mor [hPo]

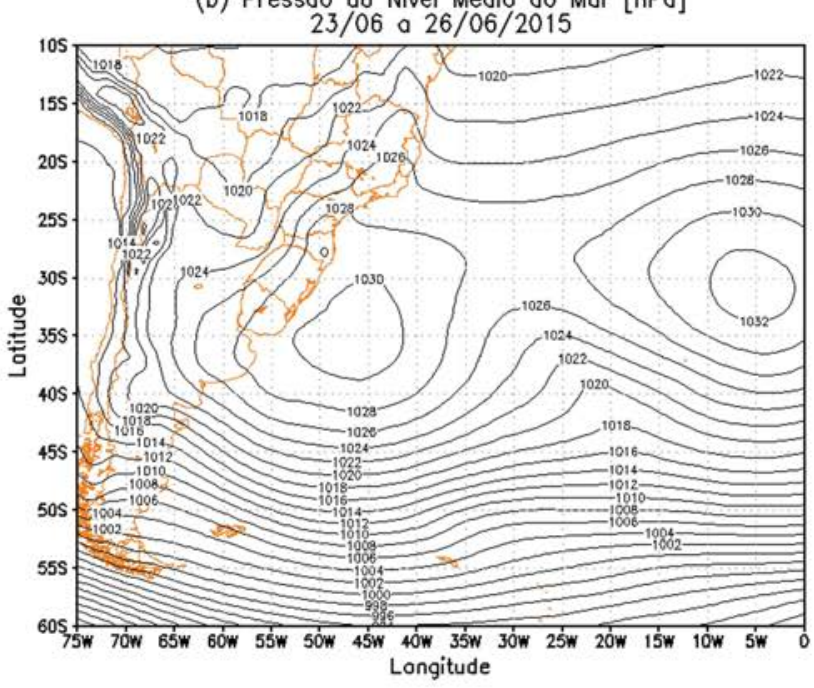

(d) Pressoo ao Nivel Medio do Mor [hPo]

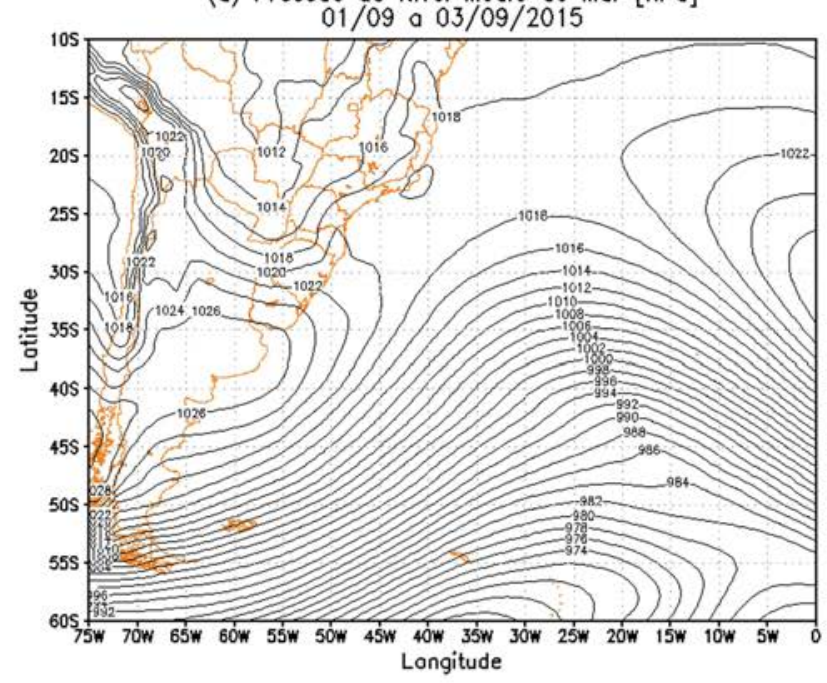

(f) Pressao ao Nivel Medio do Mar [hPo]

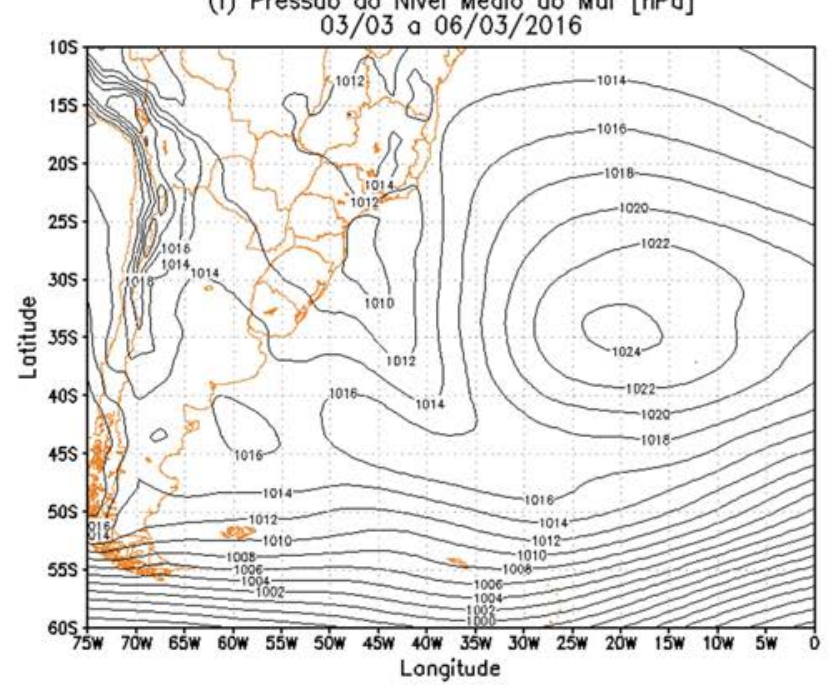

Figura 6 - Pressão ao nível médio do mar (hPa) plotada a partir da reanálise do ERA-Interim para os casos 3 (a), 4 (b), 5 (c), 7 (d), 8 (e) e 9 (f). 
(a) Vento e Mognitude $(10 \mathrm{~m})[\mathrm{m} / \mathrm{s}]$

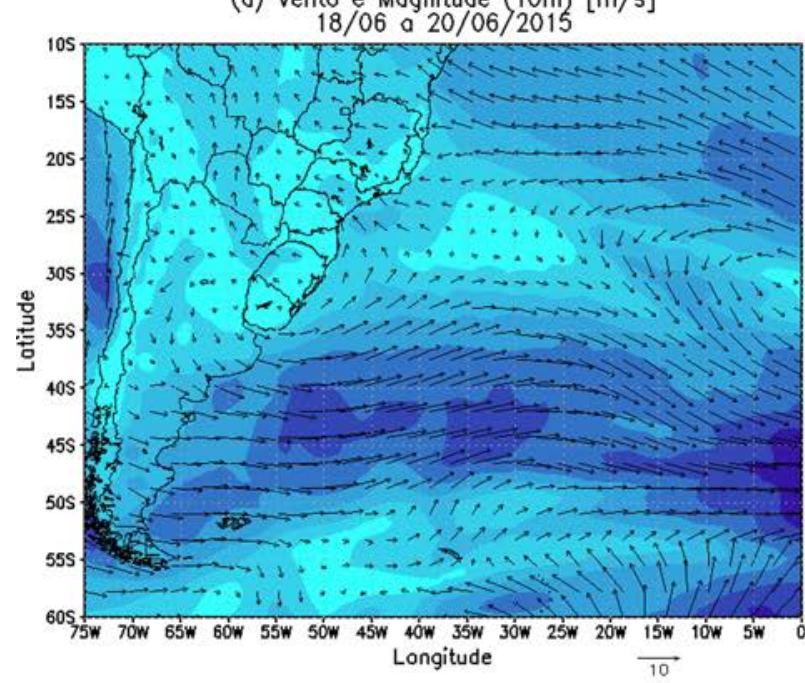

(c) Vento e Mognitude $(10 \mathrm{~m})[\mathrm{m} / \mathrm{s}]$

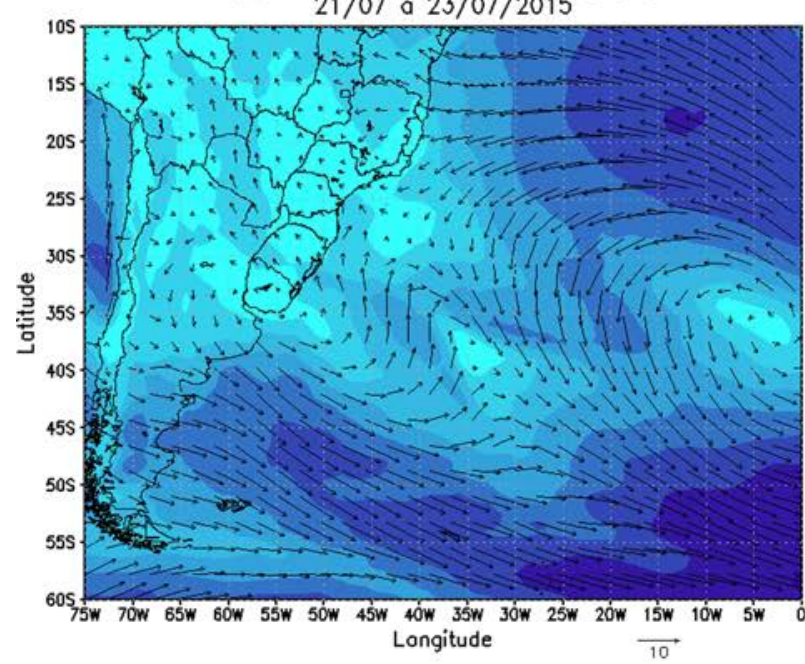

(e) Vento e Mognitude $(10 \mathrm{~m})[\mathrm{m} / \mathrm{s}]$ $17 / 10$ a $19 / 10 / 2015$

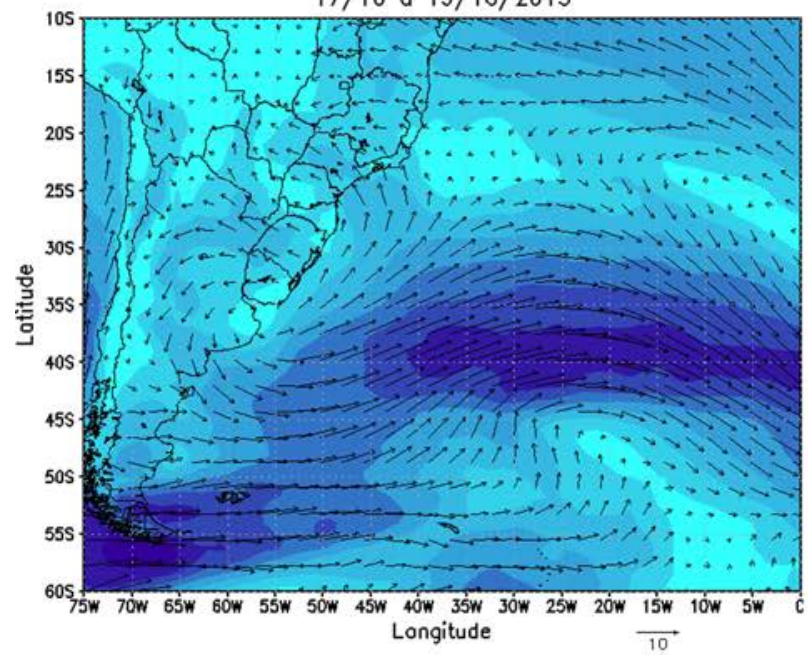

(b) Vento e Mognitude $(10 \mathrm{~m})[\mathrm{m} / \mathrm{s}]$

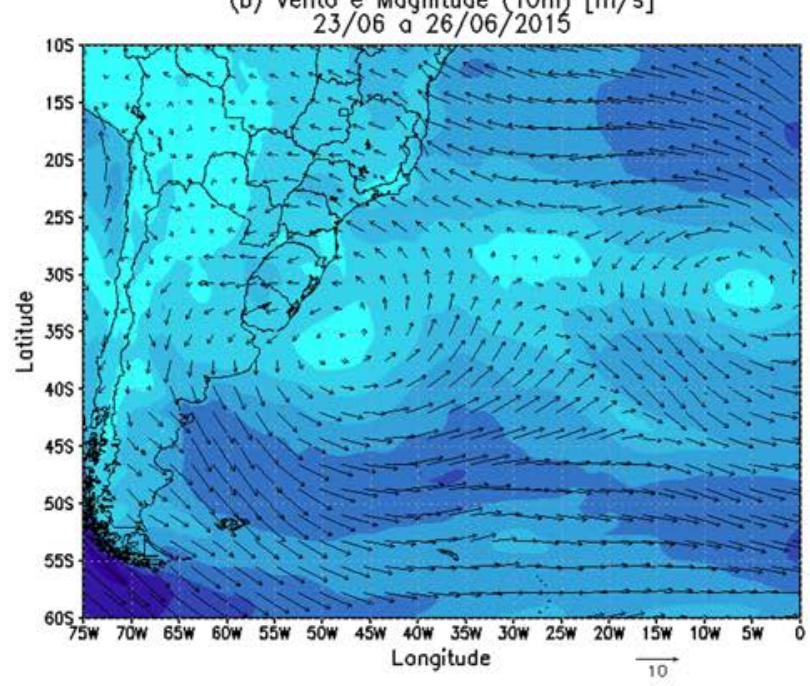

(d) Vento e Mognitude $(10 \mathrm{~m})[\mathrm{m} / \mathrm{s}]$

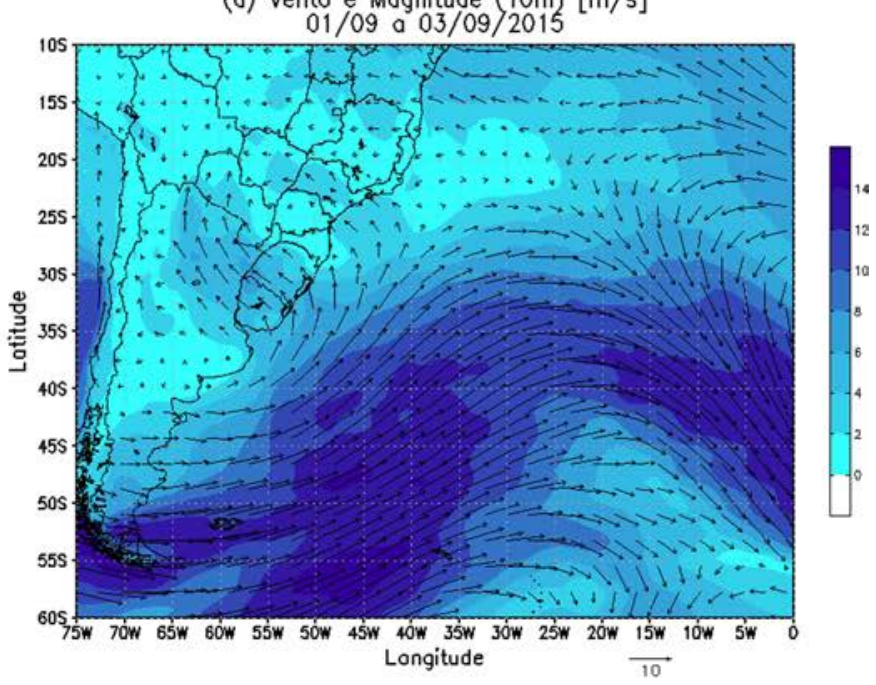

(f) Vento e Mognitude $(10 \mathrm{~m})[\mathrm{m} / \mathrm{s}]$

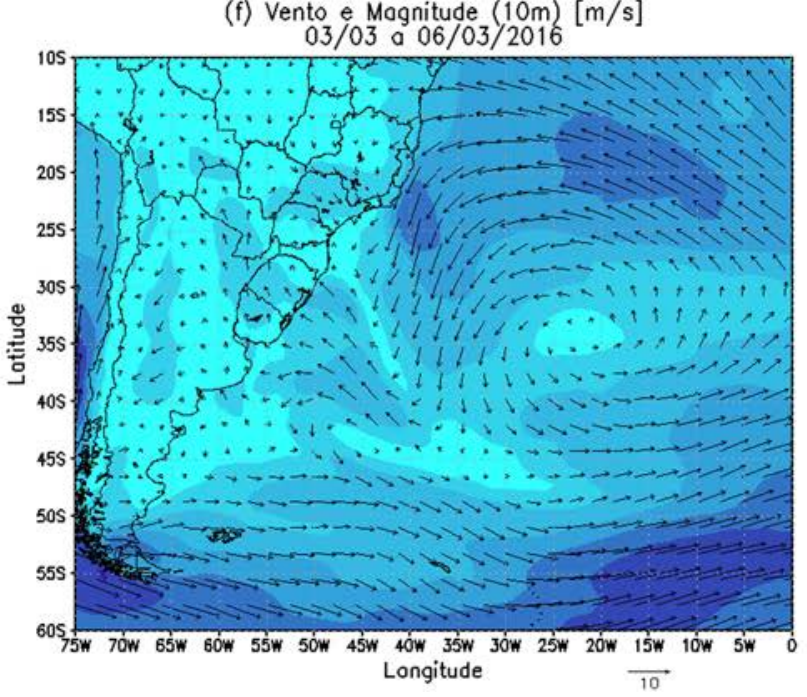

Figura 7 - Direção e magnitude do vento (m/s) plotados a partir da reanálise do ERA-Interim para os casos 3 (a), 4 (b), 5 (c), 7 (d), 8 (e) e 9 (f). 
(a) Altura [m] e direcao da ondo

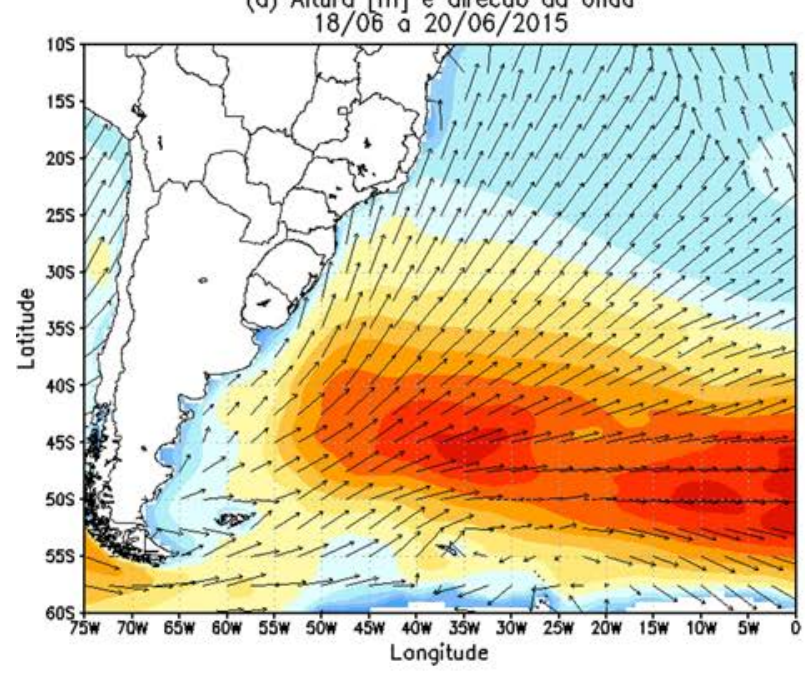

(c) Alturo [m] e direcao do ondo

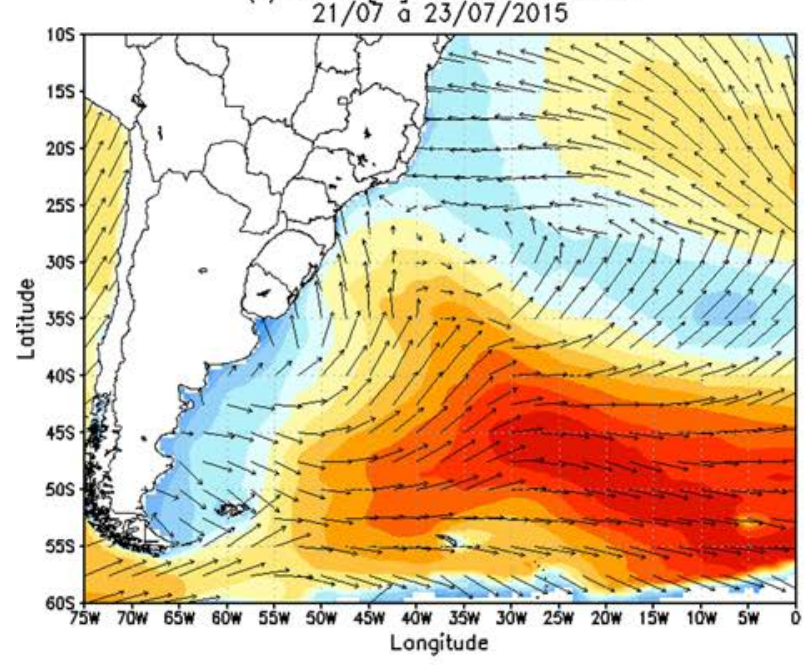

(e) Altura [m] e direcao do onda

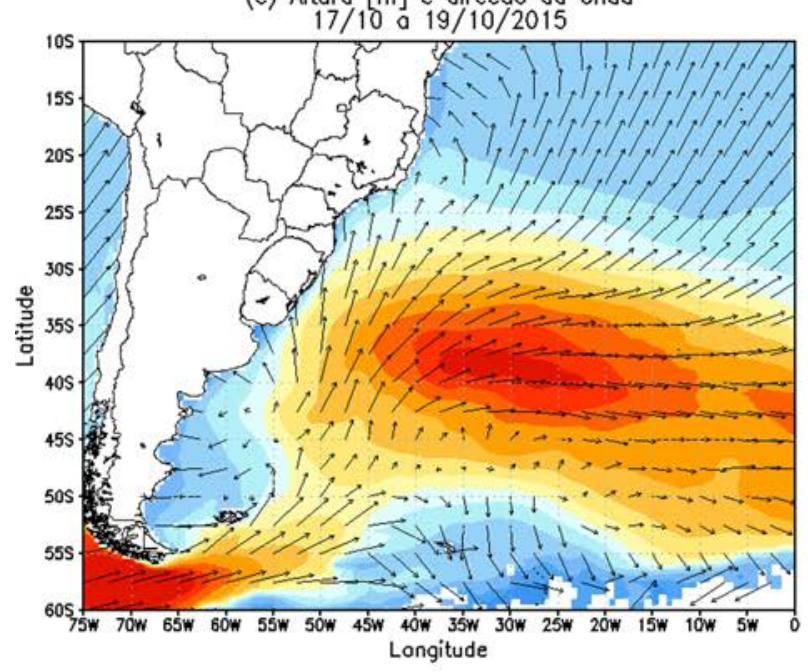

(b) Altura [m] e direcao da onda

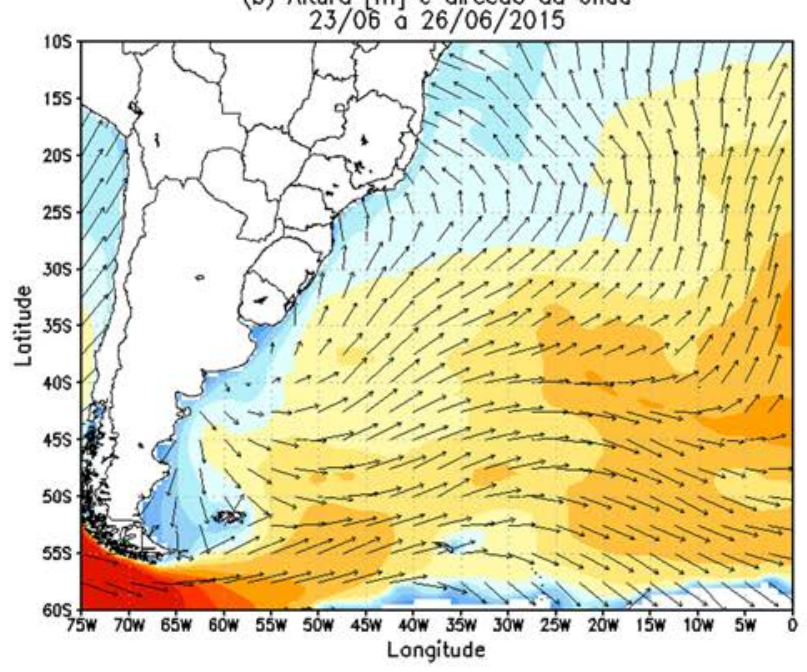

(d) Altura [m] e direcao da ondo

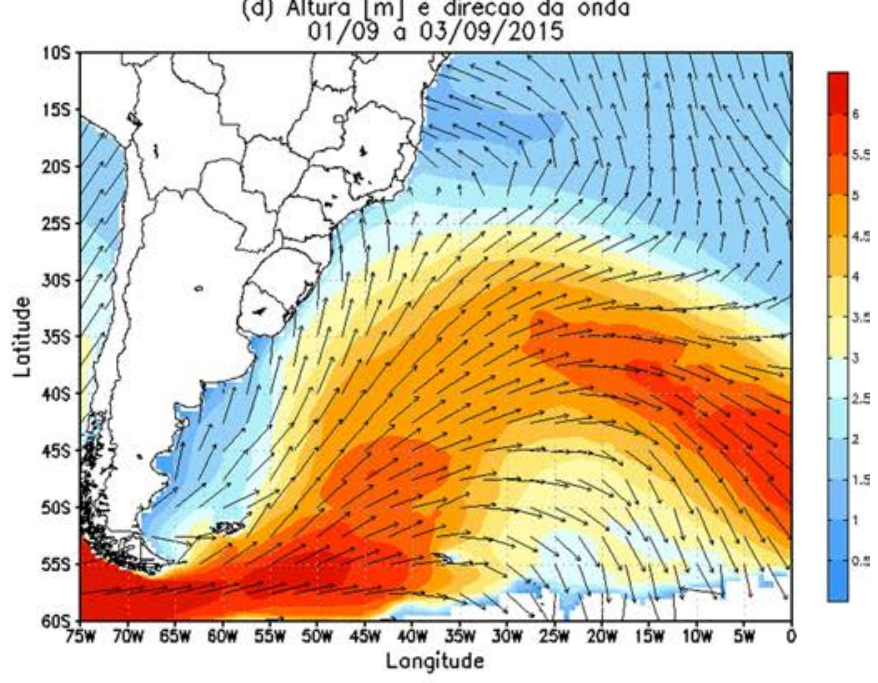

(f) Alturo $[\mathrm{m}]$ e direcao do ondo

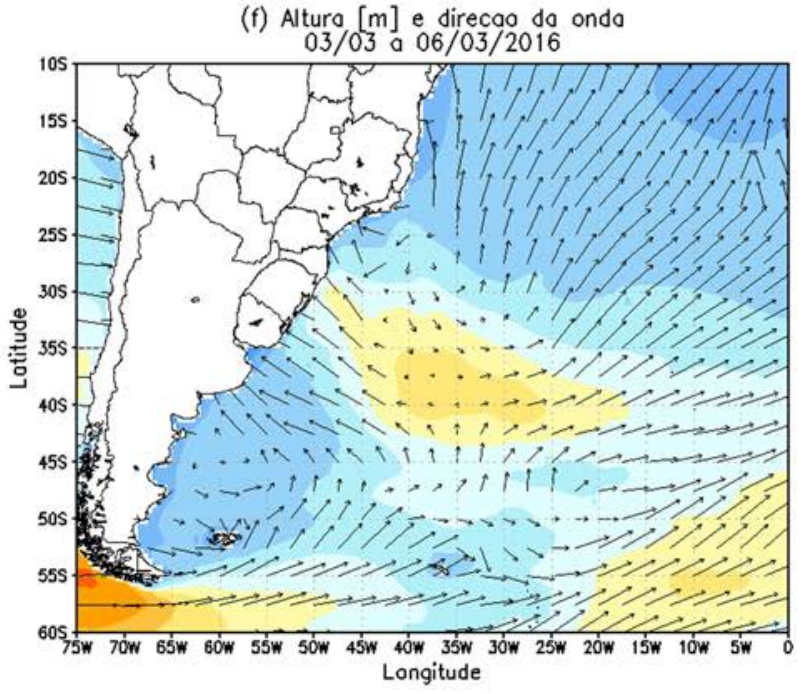

Figura 8 - Altura (m) e direção da onda plotados a partir do modelo WAVEWATCH III para os casos 3 (a), 4 (b), 5 (c), 7 (d), 8 (e) e 9 (f). 
(o) Pressoo ao Nivel Medio do Mor [hPo]

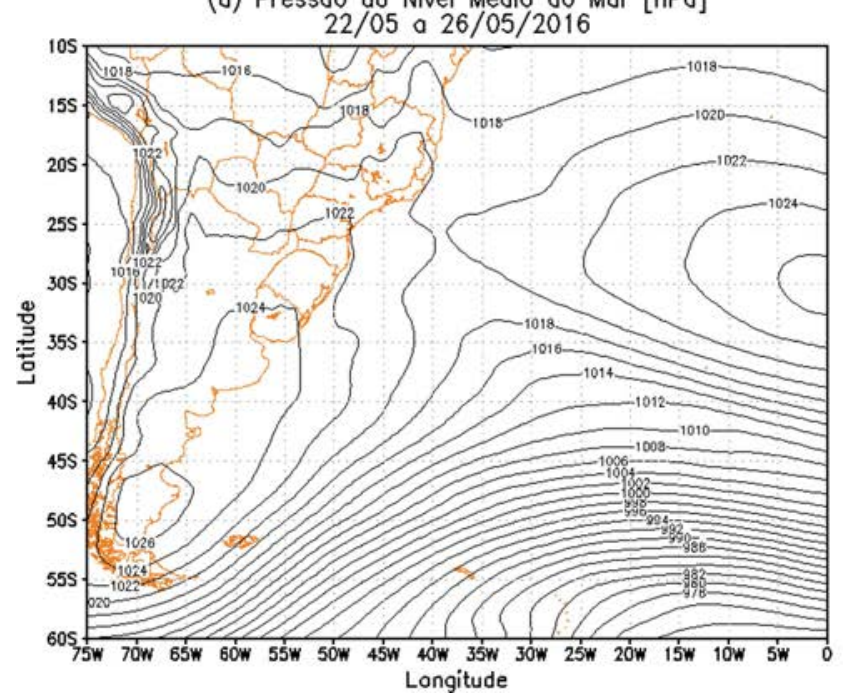

(b) Pressoo ao Nivel Medio do Mor [hPo]

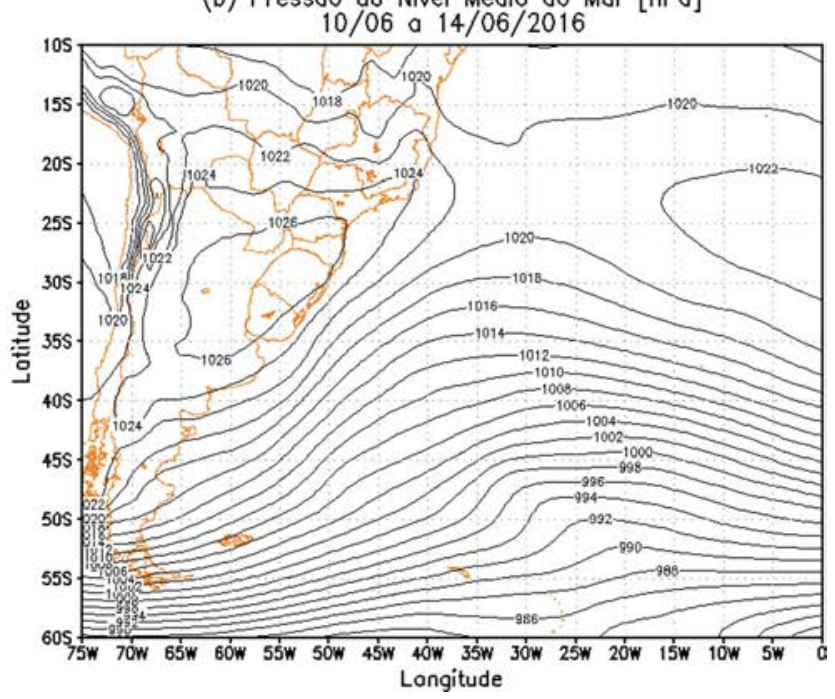

Figura 9 - Pressão ao nível médio do mar (hPa) plotada a partir da reanálise do ERA-Interim para os casos 11 (a) e 12 (b).

fica mais evidente a partir dos campos de direção e velocidade do vento para os dois casos (Fig. 10(a,b)). Como a alta pressão pós-frontal teve características mais continental, os ventos a $10 \mathrm{~m}$ foram predominantes de sudoeste, com valor médio superando os $40 \mathrm{~km} / \mathrm{h}$, principalmente no caso 12 (Fig. 10b) no litoral do Rio Grande do Sul. Pela configuração da costa brasileira, os ventos de sudoeste também favorecem ao empilhamento de água na costa, associado ao transporte de Ekman.

A partir dos campos de altura e direção da onda para os dois casos (Fig. 11(a,b)) foi possível observar que em ambos os casos havia condição para ressaca. Entretanto o caso 12 (Fig. 11b) apresentou a condição intensa, com altura média da onda de 3,5 a $4 \mathrm{~m}$ e direção de sul/sudoeste para o litoral do Sul e do Sudeste do Brasil. Isto ocorreu em função do sistema de alta pressão pós-frontal ter se posicionado mais ao norte e mais intenso em relação ao sistema do caso 11 (Fig. 11a).

\subsubsection{Padrão 4: Sistema de baixa pressão no continente}

Este último padrão identificado pode ser destacado como um caso particular que favoreceu a ocorrência de ressaca, pois ocorreu de forma isolada dentre os 12 eventos analisados. Pela análise dos campos de pressão ao nível médio do mar Fig. (12a) notou-se a atuação de quatro sistemas de pressão principais: a ASAS, com seu centro, aproximadamente, entre $20^{\circ}$ e $40^{\circ} \mathrm{S}$ e $0^{\circ}$ de longitude, outro sistema de alta pressão localizado próximo ao litoral da Argentina, o qual estava na retaguarda de um sistema de baixa pressão (ciclone extratropical) localizado ao sul da área de atuação da ASAS (com centro entre $40^{\circ}-45^{\circ} \mathrm{Se}$
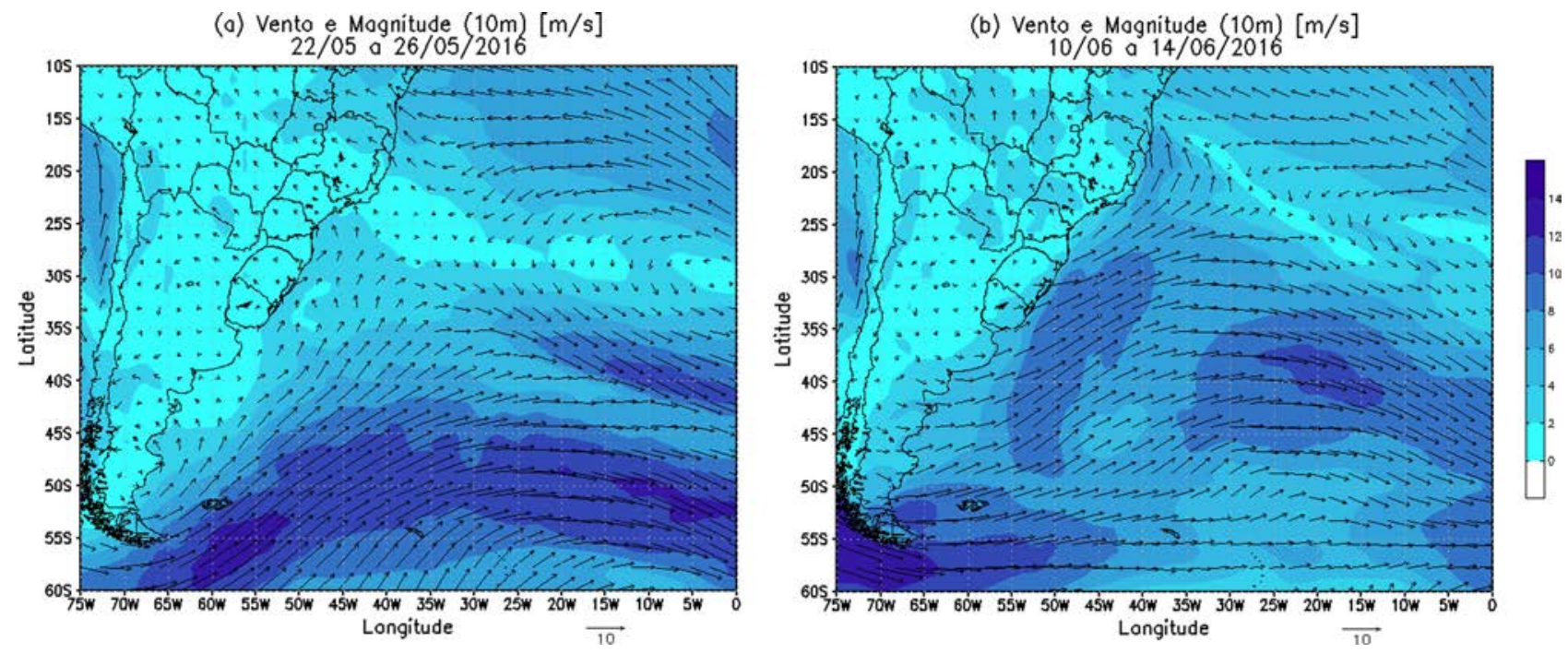

Figura 10 - Direção e magnitude do vento (m/s) plotados a partir da reanálise do ERA-Interim para os casos 11 (a) e 12 (b). 
(a) Altura $[\mathrm{m}]$ e direcao da ondo

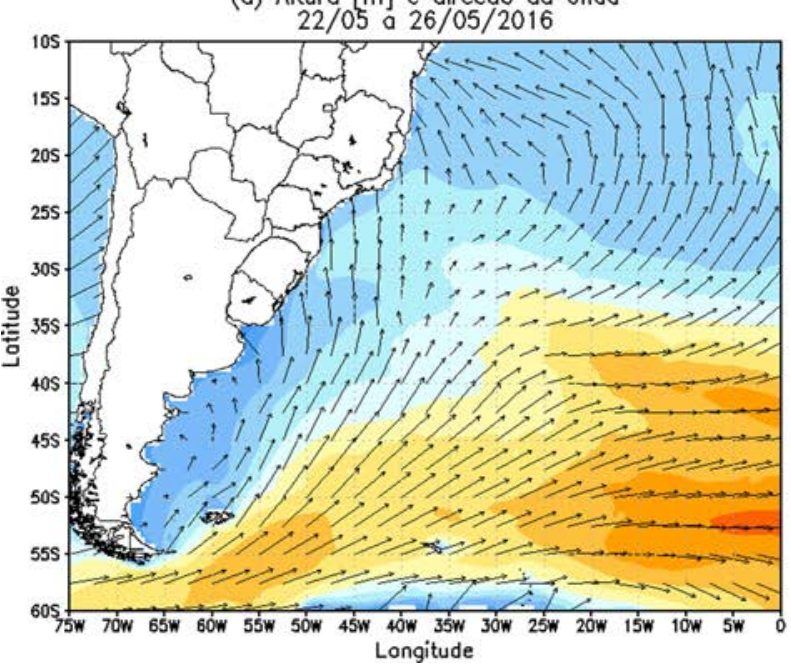

(b) Altura [m] e direcao da ondo

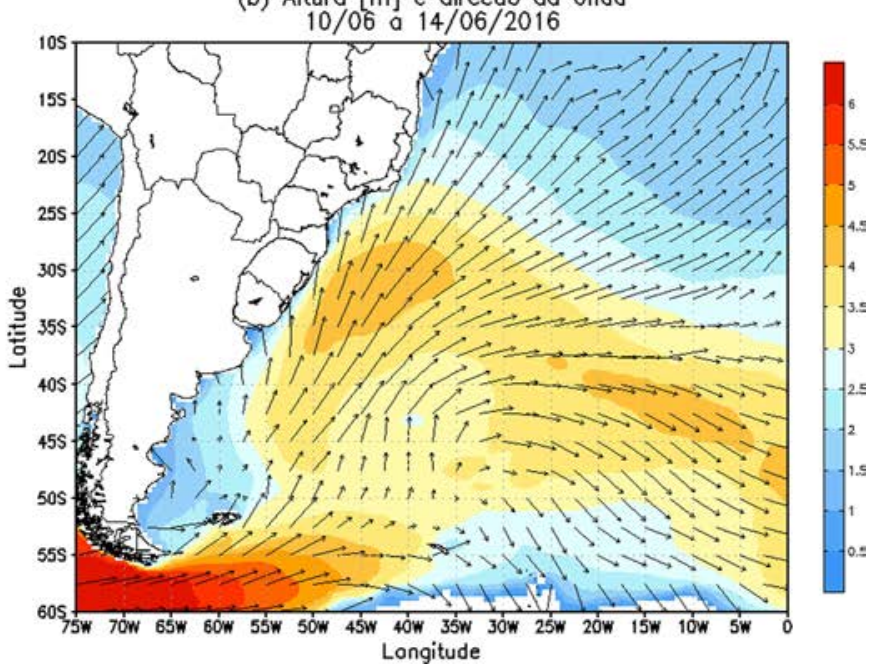

Figura 11 - Altura (m) e direção da onda plotados a partir do modelo WAVEWATCH III para os casos 11 (a) e 12 (b).

(a) Pressoo ao Nivel Medio do Mor [ $\mathrm{hPo}]$

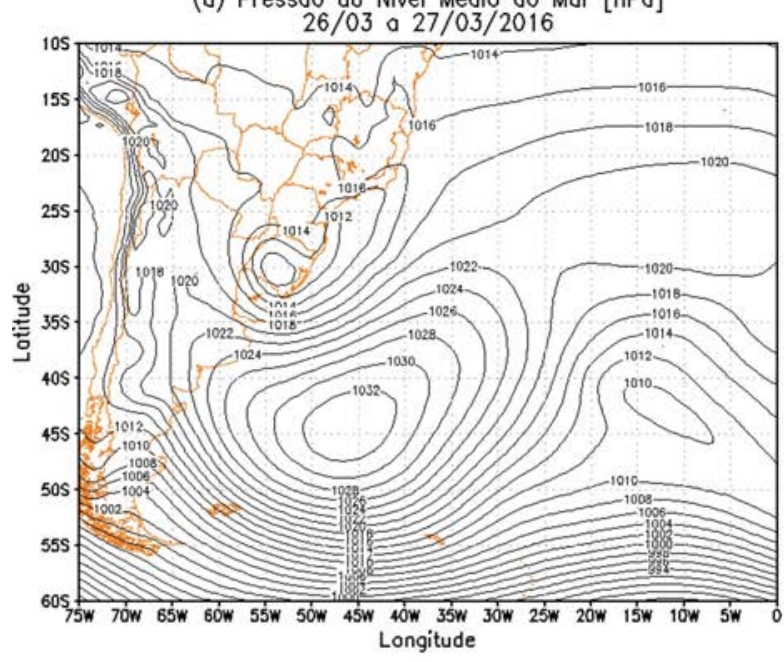

(b) Vento e Mognitude $(10 \mathrm{~m})[\mathrm{m} / \mathrm{s}]$

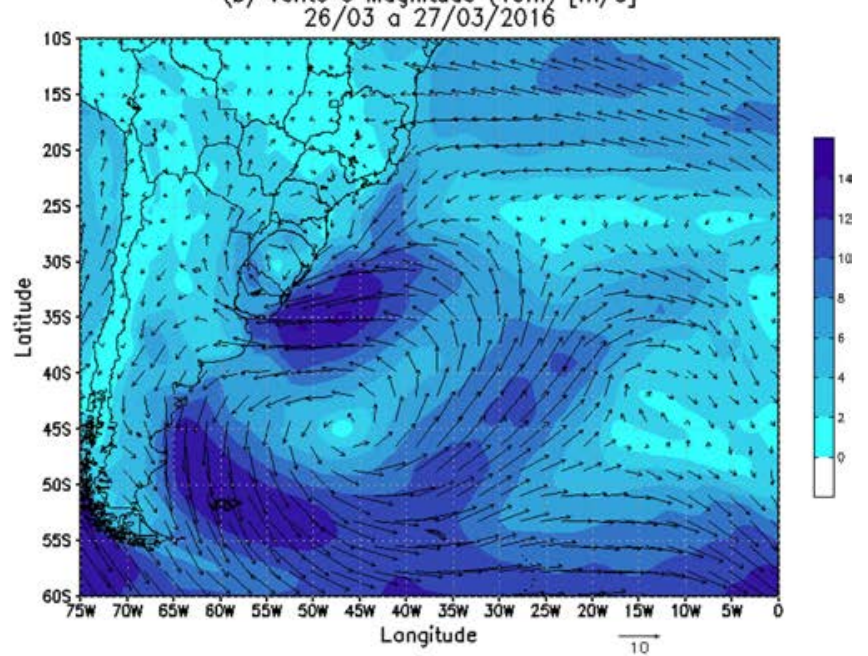

(c) Alturo $[\mathrm{m}]$ e direcao do ondo

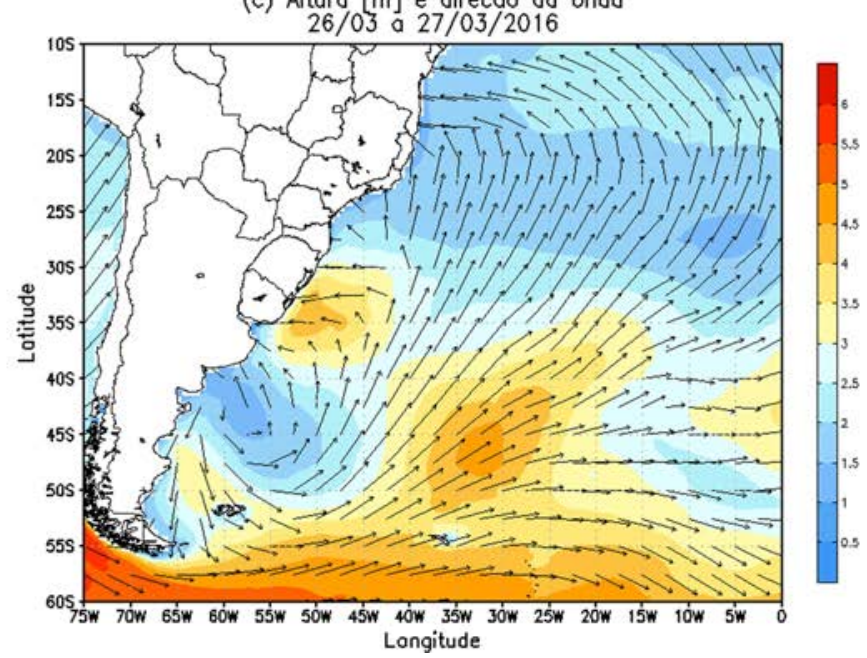

Figura 12 - Pressão ao nível médio do mar (hPa) (a), direção e magnitude do vento $(\mathrm{m} / \mathrm{s})(\mathrm{b})$ e altura $(\mathrm{m})$ e direção da onda para o caso 10. 
$\left.15^{\circ} \mathrm{W}\right)$ e, por fim, outro sistema de baixa pressão localizado sobre o Rio Grande do Sul e o Uruguai. Desta forma, a formação deste sistema de baixa pressão no continente e a presença da alta pressão mais ao sul gerou um forte gradiente de pressão atmosférica, o qual ocasionou ventos mais intensos e direção leste/nordeste (Fig. 12b), principalmente no litoral Sul do Brasil. Pela análise do modelo de ondas (WAVEWATCH III) foi possível observar que a altura média da onda ficou próxima dos $4 \mathrm{~m}$ no litoral do Rio Grande do Sul e direção sudeste (Fig. 12c).

\section{Considerações Finais}

Ao longo do período do El Niño 2015/2016, foram registrados 53 episódios de ressaca na área ALFA (A) e 39 casos na área CHARLIE (C), havendo 25 ocorrências de casos simultâneos para ambas as áreas. Tanto em A quanto em $\mathrm{C}$, os meses que registraram maior frequência de eventos de ressaca foram março, abril, maio e junho, correspondendo aos meses de outono e ao início do inverno. Dezembro foi o mês com menor ocorrência do fenômeno para a área $\mathrm{A}$, enquanto que, para a área $\mathrm{C}$, foram os meses de dezembro e fevereiro. Sazonalmente, em 2015, houve maior frequência de eventos de ressaca durante o outono, o inverno e a primavera nas duas áreas. Esta última é justificada pela presença, durante setembro, outubro e novembro de 2015 , de anomalias negativas de altura geopotencial no sudeste do continente sul-americano e no oceano Atlântico, além de ter havido maior frequência de ciclones nas latitudes subtropicais do oceano Atlântico (Pereira et al., 2017). Em 2016, os meses de outono e o início do inverno registraram, em ambas as áreas, números de ressacas muitos maiores se comparados aos registrados durante os meses de verão. Com isso, é possível concluir que, mesmo em período de El Niño muito forte, a distribuição sazonal dos eventos de ressaca se deu conforme o esperado, com base no que já é descrito pela literatura que aborda este tema.

Foram identificados padrões atmosféricos e considerados favoráveis à ocorrência de ressacas nos litorais Sul e do Sudeste do Brasil: i) Sistema de baixa pressão em superfície sobre o oceano (Ciclone extratropical) e um sistema de alta pressão na retaguarda do ciclone, formando, assim, as "pistas de vento". ii) Alta pressão pós-frontal com centro entre o Litoral do Uruguai e da Argentina. Devido a circulação anticiclônica do sistema de alta pressão mais ao sul, os ventos se tornam predominantemente do quadrante sul, e, assim, favorecendo o empilhamento de água sobre a costa. Esta condição ocorreu em 6 dos 12 casos analisados. iii) Alta pressão pós-frontal com centro sobre o Uruguai, que que apresentou uma condição sinótica muito semelhante ao padrão 2. Entretanto, o posicionamento da alta pressão ficou mais sobre o continente, favorecendo a ocorrência de ventos de sudoeste. iv) Sistema de baixa pressão no continente, o qual foi conside- rado como um caso particular, pois ocorreu isoladamente. Além disso, a configuração sinótica que contribuiu para este evento de ressaca, indicou a presença de um sistema de alta pressão ao sul do ciclone no continente, gerando um forte gradiente de pressão e ventos mais intensos no litoral do Rio Grande do Sul.

Em relação à contribuição da Maré Astronômica para os 12 eventos de ressaca estudados, verificou-se que $75 \%$ desses eventos ocorreram sob influência da Maré de Sizígia e 25\% sob influência da Maré de Quadratura, evidenciando a importância das forças gravitacionais sobre o aumento ou redução do nível do mar. Além disso, notou-se que, desses 12 eventos de ressaca, os que apresentaram maiores alturas de ondas (Casos 3, 7, 10 e 12) ocorreram nos meses de outono e inverno e sob influência da Maré de Sizígia, indicando a relação existente entre as componentes meteorológicas e astronômicas na ocorrência de ressacas e na dimensão desses eventos.

Para trabalhos futuros, o principal objetivo é desenvolver uma comparação da frequência de eventos de ressaca no litoral Sul e Sudeste do Brasil entre anos de El Niño, anos de La Niña e anos neutros, além de se estabelecer os padrões atmosféricos favoráveis, ou não, à ocorrência desses eventos. No presente trabalho essa comparação não foi possível devido ao fato dos Avisos de Mau Tempo, emitidos pelo Centro de Hidrografia do Brasil, possuírem um banco de dados muito recente, de 2006 a 2017, dificultando um estudo climatológico.

\section{Referências}

BERTIN, X. Storm surges and coastal flooding: status and challenges. La Houille Blanche - Revueinternationale de l'eau, EDP Sciences, pp. 64-70, $2016<10.1051 / \mathrm{lhb} /$ 2016020>, <hal-01453445>.

BJERKNES, J.A. Possible response of the atmosphere Hadley circulation to equatorial anomalies of ocean temperature. Tellus, v. 18, n. 4, p. 820-829, 1966.

BITENCOURT, D.P.; QUADRO, M.F.L.; CALBETI, N.O. Análise de dois casos de ressaca no litoral da região Sul no verão de 2002. In: XII Congresso Brasileiro de Meteorologia, Foz do Iguaçu, p. 3910-3917, 2002.

CAMPOS, R.M.; CAMARGO, R.; HARARI, J. Caracterização de eventos extremos do nível do mar em Santos e sua correspondência com as reanálises do modelo do NCEP no sudoeste do Atlântico Sul. Revista Brasileira de Meteorologia, v. 25, n. 2, p. 175-184. 2010.

CANDELLA, R.N.; SOUZA, S.M.L. Ondas oceânicas extremas na costa Sul-Sudeste brasileira geradas por ciclone com trajetória anormal em maio de 2011. Revista Brasileira de Meteorologia, v. 28, n. 4, p. 441-456, 2013.

CANDELlA, R.N. Estudo de Caso de Ondas no Atlântico Sul através de Modelagem Numérica. Dissertação de Mestrado, COPPE, Rio de Janeiro, 1997.

CANDELLA, R.N.; LOMONACO, D.R.; MARQUES DA CRUZ, L.M.; FERREIRA, R.S. Análises preliminares das características regionais das ondas ao longo da costa brasi- 
leira através de modelagem numérica. In: III Congresso Brasileiro De Oceanografia, Fortaleza, CE, 2008.

CAVALCANTI, I.F.A.; KOUSKY, V.E. Frentes frias sobre o Brasil. In: CAVALCANTI, I.F.A.; FERREIRA, N.J.; DIAS, M.A.F.; JUSTI M.G.A. (orgs.), Tempo e Clima no Brasil. São Paulo: Oficina de Textos, p. 135-147, 2009.

CENTRO DE HIDROGRAFIA DA MARINHA. Avisos de Mau Tempo. Disponível em: www.mar.mil.br/dhn/chm/meteo/ prev/avisos/avisos.htm. Acesso em: 30 de jun. 2017.

CHEN, B.; SMITH, S.R.; BROMVICH, D.H. Evolution of the Tropospheric Split Jet over the South Pacific Ocean during the 1986-89 ENSO Cycle. Montly Weather Review, v. 124, n. 8, p. 1711-1731, 1996.

DEE, D.P.; UPPALA, S.M.; SIMMONS, A.J.; BERRISFORD, P.; POLI, P.; et al. The ERA-Interim reanalysis: Configuration and performance of the data assimilation system. Quarterly Journal of the Royal Meteorological Society, v. 137, n. 656, p. 553-597, 2011.

FEDOROVA, N.; CARVALHO, M.H. Processos sinóticos em anos de La Niña e de El Niño. Parte II: Zonas frontais. Revista Brasileira de Meteorologia, v. 15, n. 2, p. 57-72, 2000.

FOGT, R.L.; BROMWICH,D.H.; HINES, K.M. Understanding the SAM influence on the South Pacific ENSO teleconnection, Climate Dynamics, v. 36, n. 7-8, p. 1555-1576. 2011.

GAN, M.A.; RAO, V.B. Surface cyclogenesis over South America. Monthly Weather Review, v. 119, n. 5, p. 1293-1302, 1991.

GAN, M.A.; SELUCHI, M.E. Ciclones e ciclogênese. In: CAVALCANTI, I.F.A.; FERREIRA, N.J.; DIAS, M.A.F.; JUSTI, M.G.A. (orgs.), Tempo e Clima no Brasil. São Paulo: Oficina de Textos, p. 111-126, 2009.

GRIMM, A.M.; FERRAZ, S.E.T.; GOMES, J. Precipitation anomalies in southern Brazil associated with El Niño and La Niña events. Journal of Climate, v. 11, n. 11, p. 28632880, 1998.

GRIMM, A.M.; AMBRIZZI, T. Teleconnections into South America from the tropics and extratropics on interannual and intraseasonal timescales. In: Past Climate Variability in South America and Surrounding Regions. Springer: Dordrecht, p. 159-191, 2009.

INNOCENTINI, V.; CAETANO NETO, E.S., A case study of the August 1988 South Atlantic Storm: Numerical of Wave Activity. Weather and Forecasting, v. 11, n. 1, p. 78-88, 1996.

KRUEGER, J. Análise dos Parâmetros Meteorológicos e Oceanográficos dos Eventos de Ressaca, ocorridos entre Janeiro de 2001 a Dezembro de 2010, no Estado de Santa Catarina. Monografia. Centro de Ciências Tecnológicas da Terra e do Mar (CTTMar), Universidade do Vale do Itajaí, 2011.
LIMA, D.R.O.; JUNIOR, A.R.T. Estudo de caso da atuação de um ciclone extratropical no Atlântico Sul e ocorrência de uma ressaca na costa do Rio de Janeiro em abril de 1999. In: 11 Congresso Brasileiro de Meteorologia, Rio de Janeiro, p. 2746-2751. 2000.

MARONE, E.; CAMARGO, R. Marés Meteorológicas no Litoral do Estado do Paraná: O evento de 18 de agosto de 1993. Nerítica, v. 8, n. 1-2, p. 73-85, 1994.

MUIS, S.; VERLAAN, M.; WINSEMIUS, H.C.; AERTS, J.C.J.; WARD, P.J. A global reanalysis of storm surges and extreme sea levels. Nature Communications, v. 7, n. 11969, p. 1-11, 2016.

NATIONAL OCEANIC AND ATMOSPHERIC ADMINISTRATION (NOAA). Disponível em: www.ncdc.noaa.gov/ teleconnections/enso/indicators/sst.php. Acesso em: $01 \mathrm{de}$ nov. 2017.

PARISE, C.K.; CALLIARI, L.J.; KRUSCHE, N. Extreme storm surges in the south of Brazil: atmospheric conditions and shore erosion. Brazilian Journal of Oceanography, v. 57, n. 3, p. 175-188, 2009.

PEREIRA, H.R.; REBOITA, M.S.; AMBRIZZI, T. Características da atmosfera na primavera austral durante o El Niño 2015/2016. Revista Brasileira de Meteorologia, v. 32, n. 2, p. 293-310, 2017.

PHILANDER, S.G.H. El Nino, La Nina and the Southern Oscillation, San Diego: Academic Press, 1990.

POND, S.; PICKARD, G.L. Introductory Dynnamical Oceanography. New York: Pergamon Press, 1983.

PUGH, D.T. Tides, Surges and Mean Sea Level. John Wiley \& Sons: Chichester, 472 p. 1987.

REBOITA, M.S.; ROCHA, R.P.; AMBRIZZI, T.; GOUVEIA, C.D. Trend and teleconnection patterns in the climatology of extratropical cyclones over the southern hemisphere. Climate Dynamics, v. 45, n. 7-8, p. 1929-1944, 2015.

RIBEIRO, G.G. Situações atmosféricas que propiciam marés meteorológicas, Dissertação de Mestrado, UFRGS, Porto Alegre, 2003.

SILVA, G.A.M.; AMBRIZZI, T. Summertime moisture transport over Southeastern South America and extratropical cyclones behavior during inter-El Niño events. Theoretical and Applied Climatology, v. 101, n. 3-4, p. 303-310, 2010.

STEWART, R.H. Introduction to physical oceanography. Department of Oceanography. Texas A\&M University, 2005.

TOLMAN, H.L. User manual and system documentation of WAVEWATCH version 4.18. Technical Note, 311 , 2014.

License information: This is an open-access article distributed under the terms of the Creative Commons Attribution License (type CC-BY), which permits unrestricted use, distribution and reproduction in any medium, provided the original article is properly cited. 